San Jose State University

SJSU ScholarWorks

Master's Theses

Master's Theses and Graduate Research

1993

\title{
The Effects of non-contact therapeutic touch on the parasympathetic nervous system as evidenced by superficial skin temperature and perceived stress
}

Christine Ann Louise Tharnstrom

San Jose State University

Follow this and additional works at: https://scholarworks.sjsu.edu/etd_theses

\section{Recommended Citation}

Tharnstrom, Christine Ann Louise, "The Effects of non-contact therapeutic touch on the parasympathetic nervous system as evidenced by superficial skin temperature and perceived stress" (1993). Master's Theses. 652.

DOI: https://doi.org/10.31979/etd.s5gt-6pqq

https://scholarworks.sjsu.edu/etd_theses/652

This Thesis is brought to you for free and open access by the Master's Theses and Graduate Research at SJSU ScholarWorks. It has been accepted for inclusion in Master's Theses by an authorized administrator of SJSU ScholarWorks. For more information, please contact scholarworks@sjsu.edu. 


\section{INFORMATION TO USERS}

This manuscript has been reproduced from the microfilm master. UMI films the text directly from the original or copy submitted. Thus, some thesis and dissertation copies are in typewriter face, while others may be from any type of computer printer.

The quality of this reproduction is dependent upon the quality of the copy submittied. Broken or indistinct print, colored or poor quality illustrations and photographs, print bleedthrough, substandard margins, and improper alignment can adversely affect reproduction.

In the unlikely event that the author did not send UMI a complete manuscript and there are missing pages, these will be noted. Also, if unauthorized copyright material had to be removed, a note will indicate the deletion.

Oversize materials (e.g., maps, drawings, charts) are reproduced by sectioning the original, beginning at the upper left-hand corner and continuing from left to right in equal sections with small overlaps. Each original is also photographed in one exposure and is included in reduced form at the back of the book.

Photographs included in the original manuscript have been reproduced xerographically in this copy. Higher quality $6 "$ x 9 " black and white photographic prints are available for any photograpns or illustrations appearing in this copy for an additional charge. Contact UMI directly to order.

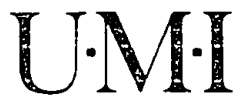

University Microfilms International

A Bell \& Howell Information Company 
The effects of non-contact Therapeutic Touch on the parasympathetic nervous system as evidenced by superficial skin temperature and perceived stress

Tharnstrom, Christine Ann Louise, M.S.

San Jose State University, 1993

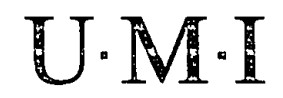

300 N. Zeeb Rd.

Ann Arbor, MI 48106 


\title{
THE EFFECTS OF NON-CONTACT THERAPEUTIC TOUCH ON
}

THE PARASYMPATHETIC NERVOUS SYSTEM AS EVIDENCED

BY SUPERFICIAL SKIN TEMPERATURE AND PERCEIVED STRESS

\author{
A Thesis \\ Presented to \\ The Faculty of the Department of Occupational Therapy \\ San Jose State University
}

\author{
In Partial Fulfillment \\ of the Requirements for the Degree \\ Master of Science
}

by

Christine Ann Louise Thamstrom, OTR

August, 1993 
APPROVED FOR THE DEPARTMENT OF OCCUPATIONAL THERAPY

surs. MCCozmack

Guy I. McCormack, MS, OTR

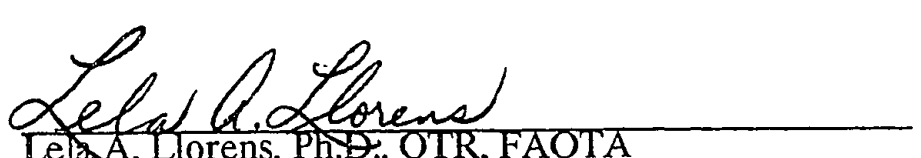

Le A Lorens, Ph., OTR, FAOTA

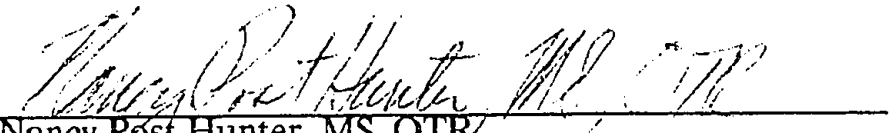

Nancy Post Hunter, MS, OTR

$\therefore$

APPROVED FOR THE UNIVERSITY

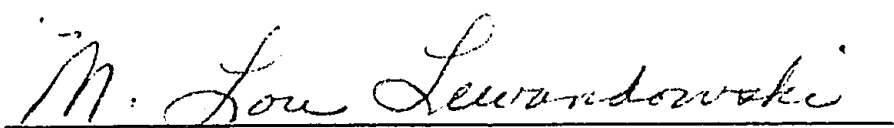




\begin{abstract}
THE EFFECTS OF NON-CONTACT THERAPEUTIC TOUCH ON THE PARASYMPATHETIC NERVOUS SYSTEM AS EVIDENCED BY SKIN TEMPERATURE AND PERCEIVED STRESS

by Christine Ann Louise Tharnstrom, OTR

Therapeutic Touch was introduced to the health professions by Dr. Dolores Krieger in 1975. Since 1961, research has produced a variety of descriptive and experimental studies to support therapeutic touch as an adjunctive technique. The purpose of this pilot study utilizing a pretest and posttest research design was to compare the superficial skin temperature and subjective stress level ratings of an experimental, sham, and control group over a 15 -minute time period. The physiological response of skin temperature was measured with a computer using a Biofeedback Microlab software package and the stress level was measured utilizing a pretest and posttest question rated on a scale of 1 to 10 . Thirty-nine participants were divided into 3 groups of 13 individuals. Analysis of variance (ANOVA) statistically revealed an increase in skin temperature and a decrease in stress level in all three groups. No significance differences were found among the three groups.
\end{abstract}




\section{Acknowledgements}

I would sincerely like to thank Professor Guy McCormack, MS, OTR, who so generously and graciously assisted me in conducting the experiment and supported me throughout the arduous process of creating a thesis. I would also like to thank Dr. Lela Llorens, Ph.D., OTR, FAOTA; Nancy Post Hunter, MS, OTR; Ruthanne Martin; and Peter Degoey for helpful comments and corrections on the numerous drafts. Special thanks to Bill Roberts for his statistical expertise and analysis. Fondest gratitude to Susan Beauchamp for her invaluable computer editing skills and nurturing dinners to prepare for long evenings of revisions and to Robin for his support for both of us. Special appreciation to the 39 students who so generously gave their time to research; without their interest, this work would not have been possible. A very special thank you to Sandra Cicuttin, MS, OTR, my co-worker, who meticulously corrected the final drafts and kept reminding me that I was "almost" finished. Finally, I would like to thank my parents, family, and friends for their love, support, and encouragement. They helped me break down my walls of resistance and procrastination to complete a rite of passage. 


\section{Table of Contents}

Page

Abstract .................. . . .

Acknowledgements ................. . . . iv

List of Tables ................... viii

List of Figures . . . . . . . . . . . . . . . . ix

Chapter 1...................... 1

Introduction .................. 1

Purpose . . . . . . . . . . . . . . 1

Statement of the Problem ............ 1

Research Question ............. . . 4

Definitions ................. 4

Conceptual Definitions . . . . . . . . 4

Operational definitions $\quad . . . . . . . . .99$

Assumptions . . . . . . . . . . . . . 10

Limitations . . . . . . . . . . . 11

Significance of the Study (. . . . . . . . 13

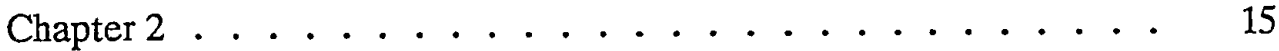

Literature Review . . . . . . . . . . 15

The Human Body as an Electromagnetic Field . . . . 15

Early Animal and Plant Studies . . . . . . . 17

Physiological Studies . . . . . . . . . . 19

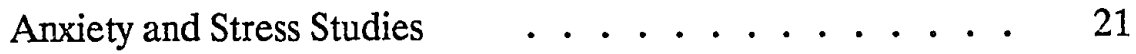

Pain Studies . . . . . . . . . . . . 23

Human Wound Healing . . . . . . . . . . 24 
Page

A Model of Human Occupation and Occupational

Performance as Conceptual Frameworks . . . . . . 24

Literature Summary . . . . . . . . . . 26

Chapter 3 . . . . . . . . . . . . . . . . 28

Design and Methodology . . . . . . . . . . . 28

Research Question . . . . . . . . . . 28

Research Design . . . . . . . . . . . 28

Sample ................ . . . 29

Procedure for Data Collection . . . . . . . . 29

Data Analysis . . . . . . . . . . . 33

Chapter 4 . . . . . . . . . . . . . 35

Data........................ 35

Sample Characteristics . . . . . . . . 35

Individual Performance Across Three Time Periods $\quad$. . . 36

Skin Temperature Data and Results . . . . . . . 38

Perceived Stress Level Data and Results ～. . . . . . 49

Research Question Findings . . . . . . . . 54

Summary ............... . . . 54

Chapter 5................... 56

Discussion of Results with Implications for the Profession $\quad$. 56

Discussion of Results . . . . . . . . . . 56

Implications for the Profession of Occupational Therapy 57

Recommendations for Further Study . . . . . . . 56

References ........................ 60 
Page

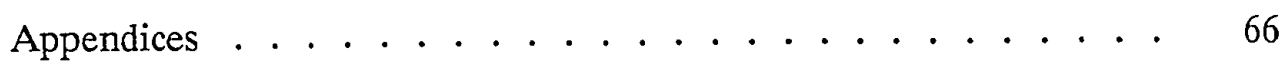

Appendix A - Prequestionnaire for Descriptive Information and Pretest Stress Level Rating _. . . . . 68

Appendix B - Consent Form to Participate in Research at San Jose State University ． . . . . . 70

Appendix C - Experimental Subjects' Bill of Rights _ . . . . 73

Appendix D - Postquestionnaire and Posttest Stress

Level Rating . . . . . . . . . . 75

Appendix E - Letters of Permission for Reprinting Illustrations . . . . . . . . . . 77 


\section{List of Tables}

Page

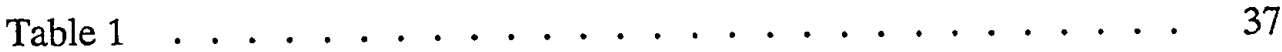

Coefficients of Variance Across Three Time Periods

Table 2 ....................... 40

Means and Standard Deviations of Skin Temperature for Three

Groups Over a 15-Minute Time Period

Table 3 ................. 42

Means and Standard Deviations (SD) of Skin Temperature for

Three Groups Over Thr e Averaged Time Periods

Table 4 ...................... 43

Means and Standard Deviations of Skin Temperature Averaged in

All Three Groups Over Three Time Periods

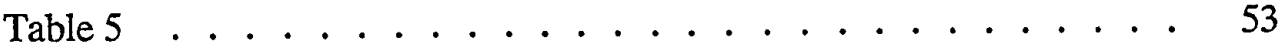

Pretest and Posttest Stress Level Ratings

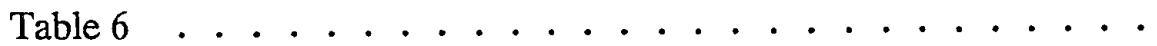

Pretest and Posttest Stress Means and Standard Deviations 


\section{List of Figures}

Page

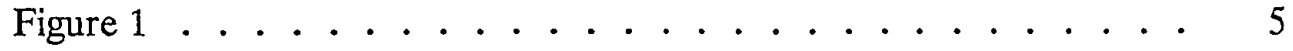

Mechanism of touch at the cardiac plexus and mesenteric plexus

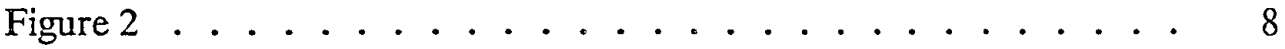

Vasodilation

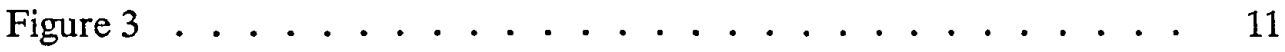

Pattern of Equipotential Direct Current Field Lines in Human

Beings. Thermistor Placement Below the Xyphoid Process (x).

Figure 4 .................... 39

Bar Graph for Mean Skin Temperature Over Time For

Three Groups

Figure 5..................... . . . 44

Skin Temperature Increases Over Three Time Periods in Three

Groups

Figure 6 .................. . . 45

Mean Skin Temperature Increases Over Time in Three Groups

Figure 7 . . . . . . . . . . . . . 46

Bar Graphs for Three Non-Contact Therapeutic Touch Subjects

Figure 8 . . . . . . . . . . . . . . . 47

Bar Graphs for Two Non-Contact Therapeutic Touch Subjects

Figure 9 . . . . . . . . . . . . . . . 48 48

Bar Graphs for Three Non-Contact Sham Therapeutic Touch Subjects

Figure 10 ...................... 50

Bar Graphs for Two Non-Contact Sham Therapeutic Touch Subjects 
Figure 11 .................... 51

Bar Graphs for Three Control Subjects

Figure 12 ................... 52

Bar Graphs for Two Control Subjects 


\section{CHAPTER 1}

\section{INTRODUCTION}

\section{Purpose}

The purpose of this study was to explore the effect of non-contact therapeutic touch on the parasympathetic nervous system as measured by a change in superficial skin temperature and subjects' perception of stress.

\section{Statement of the problem}

Therapeutic touch is a controversial modality. This study was designed to measure a physiological response to the modality of touch. Occupational therapy often uses relaxation as an adjunct to therapeutic modalities. Literature to date has shown that non-contact therapeutic touch is used to induce a physiological relaxation response (Krieger, 1974). This appears to be similar to the condition of reduced tension described by Benson (1975) as the "Relaxation Response," which he believes to be an altered state of consciousness produced by a meditative state. The relaxation response is the state which brings on bodily changes that decrease heart rate, decrease pulse rate, decrease respiration, lower metabolism, and brings the body back to a homeostatic state (Benson, 1975).

The state of the practitioner's consciousness while therapeutic touch is administered has been termed a "healing meditation" (Peper \& Pollini, 1976). As the practitioner administers non-contact therapeutic touch, the client exhibits an increased predominance of alpha activity in the brain wave pattern (Krieger, Peper, 
\& Ancoli, 1979). Benson (1975) had noted the presence of alpha waves in electroencephalographic (EEG) records as a characteristic of the meditative state. Alpha waves are rhythmic waves which occur at a frequency of between 8 and 13 waves per second and are found in the EEG of almost all normal adults when they are awake in a quiet, resting state. Visual sensation causes immediate cessation of the alpha waves and these are then replaced by low voltage, asynchronous beta waves which occur at frequencies of more than 14 cycles per second and as high as 25-250 waves per second. Beta waves occur during activation or tension of the central nervous system (Guyton, 1991). Other physiological indices supporting a meditative condition include a reduction in skin conductance level (Glueck \& Stroebel, 1975; Wallace, 1970), a decraase in muscle tension (Karabelher, Bhole, \& Gharste, 1979), and an increase in skin temperature (McDonagh \& Eugene, 1972). The conscious state of relaxation is characterized by a decrease in muscle tone and an increase in parasympathetic nervous system activity. The term "trophotropic" is often used to describe this state of the autonomic nervous system continuum (McCormack, 1992). Dr. Walter Hess, a Swiss Nobel Prize winner, produced the neurological change associated with the "fight or flight" response by stimulating a part of the cat's brain within the hypothalamus. He stimulated another area within the hypothalamus and elicited a response whose physiological changes were similar to those measured during the practice of meditation and opposite to the sympathetic response. This was termed trophotropic and described as a "protective mechanism against overstress belonging to the trophotrophic system and promoting a restorative process" (Benson, 1975).

External changes in skin temperature reflect the activity of the circulatory, endocrine, and autonomic nervous systems which produce internal physiological responses. Biofeedback uses skin temperature as an indirect measure of blood flow. 
Blood is metabolically warmed at the core of the body and then distributes heat to the skin as it circulates. As blood flow increases, the heat from the increased blood flow will create an increase in skin temperature. Thus, an increase or decrease in skin temperature will reflect a change in circulation (Mehler, Miller, Antonucci, \& Cochran, 1986). Control of vascular activity is primarily mediated by the sympathetic branch of the autonomic nervous system. Skeletal muscle fibers are surrounded by blood vessels; therefore, a decrease in activity of the sympathetic nervous system causes the muscle fiber to relax because of an increase in the diameter of blood vessels and an increase of blood flow to a given area of the body (Mehler, Miller, Antonucci, \& Cochran, 1986).

Theoretically, non-contact therapeutic touch should influence the parasympathetic nervous system with a subsequent increase in skin temperature. It has been documented that a naturally occurring direct current (DC) follows much the same pattern as peripheral skin temperature (Becker \& Selden, 1985). Changes in the peripheral vasculature and peripheral blood flow is a basic homeothermal mechanism which is more variable at the periphery than the core (Harrison, Weiner, Tanner, Barnicott, \& Reynolds, 1983). Tyler and Warfield (1985) have used a basic law of physics, the Stefan-Boltzman law to support thermographs. This law states, "A solid body heated to a temperature above absolute zero will radiate energy in the form of electromagnetic waves at a rate proportional to the fourth power of the temperature." The human body maintains a temperature of $98.6 \mathrm{~F}$, thus it produces electromagnetic waves.

In a thesis completed at San Jose State University, entitled, The Effects of Therapeutic Touch on Muscle Tone, Post (1990), measured the effects of therapeutic touch and sham therapeutic touch on muscle tension on the frontalis muscle. For further studies Post recommended the inclusion of a control group which received 
no intervention for a baseline comparison as the results of her 1990 study were inconclusive.

This study addressed the need to include a control group which was considered to be a critical omission from previous research. The use of therapeutic touch as an adjunctive technique to induce a relaxation response was also addressed.

\section{Research Question}

The research question posed in this study was stated as follows: Does the application of non-contact therapeutic touch influence the parasympathetic nervous system as evidenced by a relaxation response characterized by an increase in superficial skin temperature and a decrease in perceived level of stress when compared to a non-contact sham therapeutic touch group and a control group receiving no intervention?

\section{Definitions}

\section{Conceptual Definitions}

Conceptual definitions for this study are stated as follows:

Cardiac Plexus: (The site of influence for the parasympathetic nervous system.) The concentration of parasympathetic nerve endings and blood vessels located beneath the sternum (see Figure 1 for visual representation of cardiac plexus). The cardiac plexus is a cluster of nerves and blood vessels which surrounds the heart area. The parasympathetic system controls heart rate by way of the parasympathetic fibers carried to the heart in the vagus nerve from the medulla directly to the heart. Principally, the parasympathetic system causes a marked 


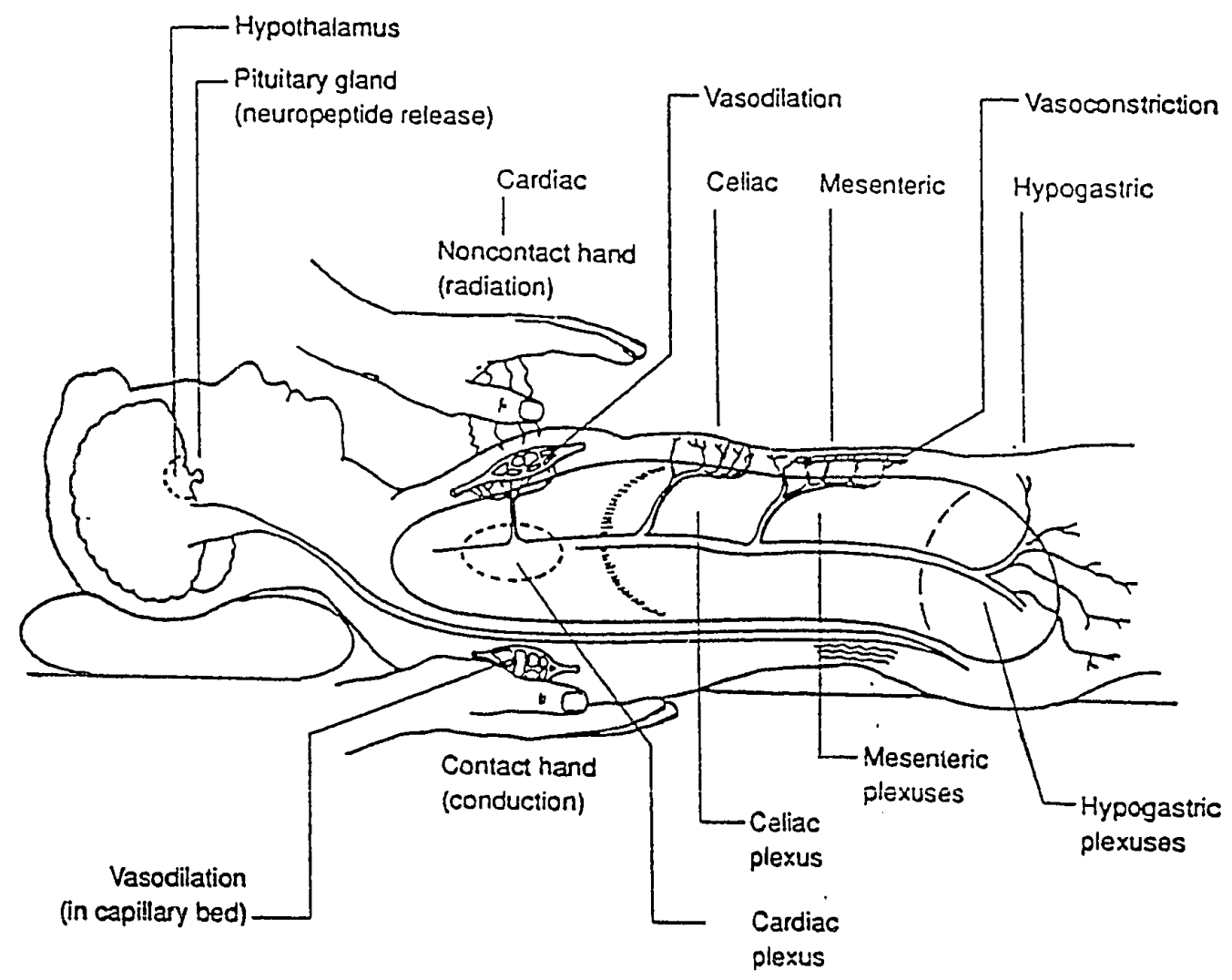

Figure 1. Mechanisms of Touch at the Cardiac Plexus and Mesenteric Plexus

Note: From Therapeutic Use of Touch (p. 170) by G. L. McCormack, 1991, Tuscon, Arizona: Therapy Skill Builders. Copyright 1991 by Communications Skill Builders. Reprinted by permission (see Appendix E). 
decrease in heart rate and a slight decrease in contractibility (Guyton, 1991). Life Energy Field: A concept linked to a field theory and seen as exhibiting the characteristics of a force field (Macrae, 1988). A field is generally defined as a continuous quality or condition throughout space. Since life is "an inherent principle in the dynamics of the universe," the assumption is made that the vital energy is also a force field. Thus all living things share a generalized life energy field, in the same way that all physical objects in space are subject to gravity (Macrae, 1988).

In a state of health, the life energy freely flows in, through and out of the organism in a balanced manner nourishing all the body. In disease, the flow of energy is obstructed, disordered, and or depleted (Heidt, 1991).

Mesenteric Plexus: (The site of influence for the parasympathetic nervous system.) The mesenteric plexus represents the parasympathetic nerve ending located around the navel region of the abdomen which includes and surrounds the gastrointestinal system (see Figure 1 for visual representation of mesenteric plexus). Parasympathetic stimulation increases the overall degree of activity of the gastrointestinal tract by promoting peristalsis and relaxation of the sphincter (Guyton, 1991). The parasympathetic nervous system is transmitted almost entirely along the vagus nerve and provides extensive innervation to the esophagus, stomach, pancreas, and large intestine. The postganglionic neurons of the parasympathetic nervous system are mainly located in the mesenteric and submucosal plexus, so that stimulation of the parasympathetic nervous system enhances gastrointestinal function (Guyton, 1991).

Parasympathetic Nervous System: Part of the autonomic nervous system (ANS). Almost three-fourths of all parasympathetic nerve fibers are in the vagus nerve, which serves the entire thorasic and abdominal regions of the body (Miller \& 
Keane, 1987). The parasympathetic nervous system acts to conserve the body's resources and restore homeostasis; it slows the heart, reduces blood pressure, and prepares the body for relaxation and rest (Kandle \& Schwartz, 1985).

Perceived: To attain awareness or understanding of; to become aware of through the senses (Webster, 1988).

Relaxation Response: A physiological state of relaxation whereby the autonomic nervous system (ANS) shifts its predominance toward the parasympathetic end of the continuum. As described by Benson (1975), the relaxation response is a lessening of tension. Physiological effects include a decrease in pulse rate, respiratory rate, oxygen consumption, carbon dioxide production, elimination, blood pressure, metabolic rate, and muscle tension. Additionally, relaxation can cause peripheral vasodilation and an increase in peripheral temperature (Miller \& Keane, 1987) (see Figure 2). The mental and physiological state of acquiescence.

Temperature Sensor: A small sensory electrode designed to measure skin temperature. The tip of the temperature sensor contains a thermistor encased in glass and coated with a plastic material.

\section{Therapeutic Interventions}

1. Non-Contact Therapeutic Touch: The process of holding the hands over the body with intentional transfer of energy. The practitioner acts as an instrument to mentally and physically focus and direct energy from the environment to the client. The energy follows the intent to help or heal (Newshaw, 1989). Non-contact therapeutic touch is based on the fundamental assumption that there is a universal life energy that sustains all living organisms; the Eastern therapeutic system has used this premise for ages. Non-contact therapeutic touch practitioners have learned to attune to the universal life field through a conscious intent or 


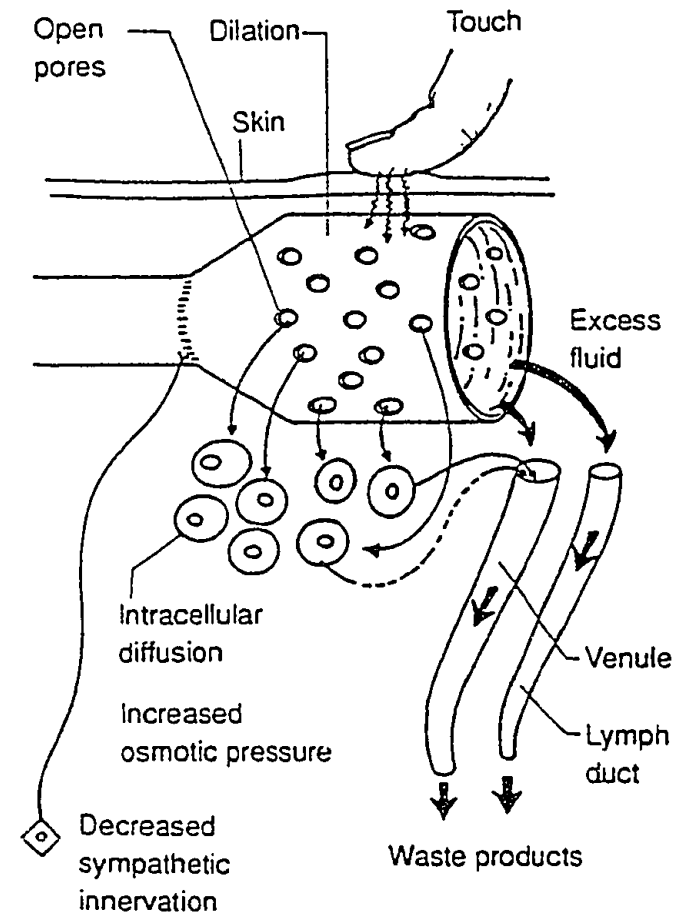

Relaxation response

\section{Figure 2. Vasodilation}

Note: From Therapeutic Use of Touch (p. 90) by G. L. McCormack, 1991, Tuscon, Arizona: Therapy Skill Builders. Copyright 1991 by Communications Skill Builders. Reprinted by permission (see Appendix E). 
intentionality and direct the life energy into the participant to enhance their vitality (Macrae, 1988). Since the localized field of the participant penetrates and extends beyond the body, actual physical contact is not necessary for therapeutic touch (Macrae, 1988). During the intervention the practitioner tries to assist the participant to retain the energy flow and to establish new habit patterns which are more open and balanced.

2. Non-Contact Sham Therapeutic Touch: The process of holding the hands over the body with the component of intentionality eliminated in the transfer of energy. The practitioner does not mentally focus on the intent to help or heal and does not maintain the alpha state. This intervention is used to measure the placebo effect.

3. No Therapeutic Touch Group: No touch intervention is given by the practitioner.

Stress: A state resulting from a stress; one of bodily or mental tension resulting from factors that to tend to alter an existent equilibrium (Webster, 1988).

Superficial Skin Temperature: The degree of sensible heat and cold, expressed in terms of a specific scale (Miller \& Keane, 1987). Heat conduction to the skin by the blood is controlled by the degree of vasodilation of the arterioles and arteriovenus anastomoses that supply blood to the venous plexus of the skin. This vasocilation is controlled almost entirely by the autonomic system in response to changes in the body core and environmental temperature (Guyton, 1991).

\section{Operational Definitions}

Operational definitions for this study are stated as follows:

Paper First Aid Tape: Adhesive made from porous paper. Non-porous tape causes heat to build up around the temperature sensor and result in an inaccurate 
measurement.

Perceived Level of Stress: Measure of stress as indicated by the subjects on a scale of 1 to 10 with 1 indicating a low level of stress and 10 indicating a high level of stress (see Appendix A).

Practitioner's Localization of Cardiac Plexus: The practitioner holds his or her left hand, palm down, 1 in. below the xyphoid process with middle finger and distal palmar arch horizontal between the nipples and 3 to $8 \mathrm{~cm}$ above the area (see Figure 1).

Practitioner's Localization of Mesenteric Plexus: The practitioner holds his or her right hand, palm down, 3 to $8 \mathrm{~cm}$ above the naval with middle finger and distal palmar arch horizontal to the navel (see Figure 1).

Superficial Skin Temperature: Surface skin temperature measured by a thermistor taped in midline one in. below the xyphoid process in the abdominal area. Immediately beneath the skin is a continuous venous plexus that is supplied by the inflow of blood from the skin capillaries and creates a temperature change. Change is read in Fahrenheit degrees ( $\left.{ }^{\circ} \mathrm{F}\right)$ and readings taken at 60 -second intervals for 15 minutes.

Temperature Sensory: Skin temperature measured by one sensory electrode with the results read on a computer printout at 60 -second intervals for 15 minutes. The sensory electrode is attached with paper tape to the midline of the abdomen 1 in. below the xyphoid process and measures the temperature in Fahrenheit degrees (see Figure 3).

\section{Assumptions}

This study was based on the following assumptions:

1. All the subjects were in good health. 


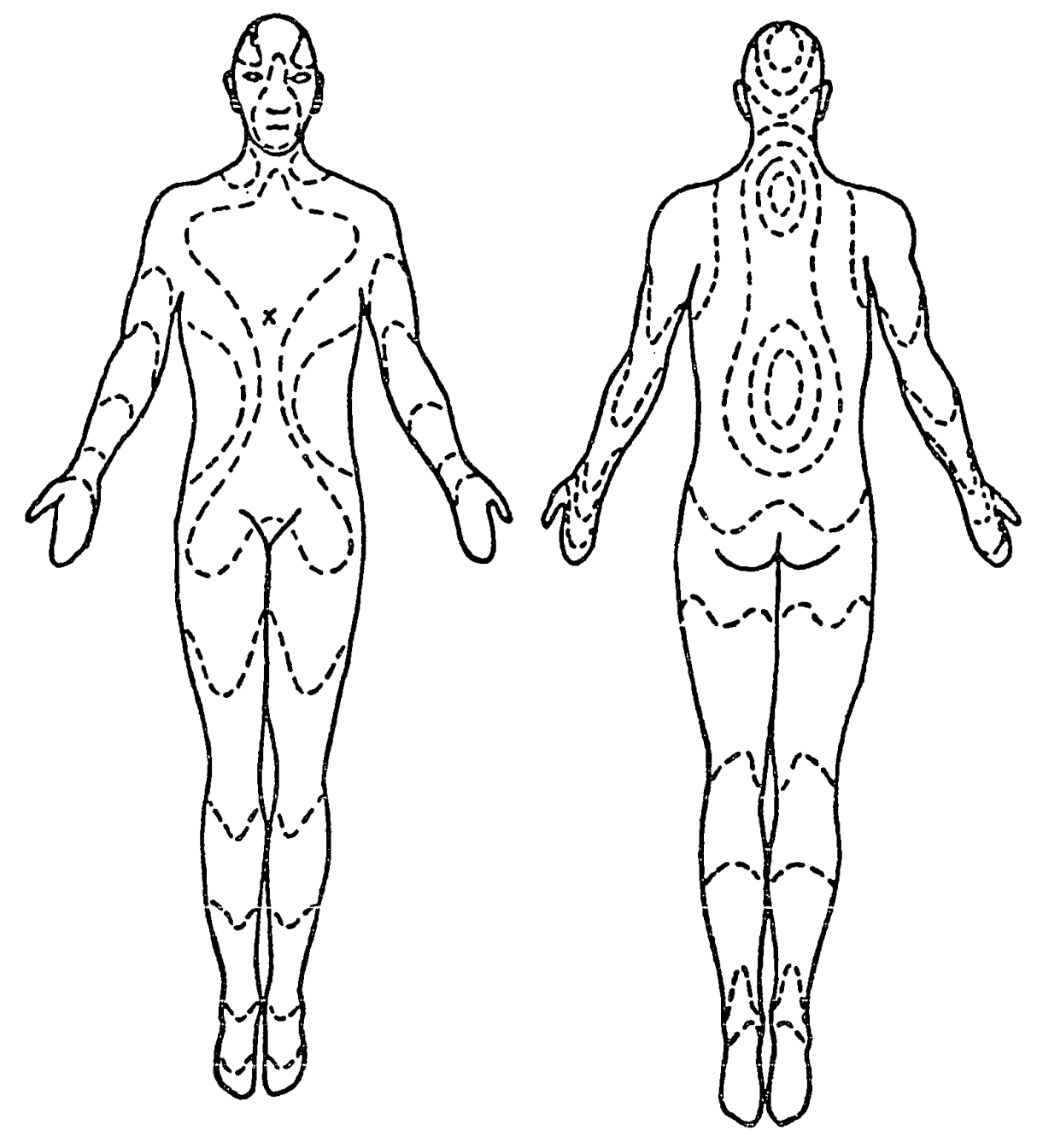

Figure 3. Pattern of Equipotential Direct Current Field Lines in Human Beings Thermistor placement below the xyphoid process $(\mathrm{x})$.

Note: From The New York State Journal of Medicine (pp 1169-1176) by R. O. Becker, 1962. Reprinted by permission (see Appendix E). 
2. The Biofeedback Microlab Human Relations Media software program and Apple IIe computer were not defective.

3. The validity and the reliability of the study were dependent upon the accuracy of the use of the Biofeedback Microlab Human Relations Media software which was run on the Apple IIe computer system.

\section{Limitations}

The limitations of this study were as follows:

1. The environment available for the study was moderately controlled for temperature and noise, but noise from the outside environment could not be controlled. Extraneous noise may have skewed the results because the participants may have been distracted and unable to relax. Ear muffs were used to minimize the effect.

2. The subjects for the study were a convenience sample and were randomly assigned to three groups.

3. The design of the pretest and posttest questionnaire could have biased the results in relation to the before and after stress rating. Subjects knew at the beginning of the study that they would be asked to rate their perceived level of stress at the end of the study.

4. Non-contact therapeutic touch is a modality that is inherently difficult to control for consistency and quality of application. It was executed by a practitioner trained in the application of non-contact therapeutic touch. In a fully controlled situation, the practitioner would be monitored for the alpha state on an electroencephalograph (EEG), but this requires a doctor's prescription and the cost is beyond the scope of this study.

5. The results of this study cannot be generalized to a physically challenged 
population since the population studied was assumed to be healthy and normal.

6. Neuroimaging techniques such as positron emission tomography (PET) or thermography could be used to display heat radiation in the form of electromagnetic waves between two human fields during non-contact therapeutic touch; however, the cost was beyond the scope of this study.

7. It was impossible to eliminate from the treatment effect the placebo effect that arose from implicit and explicit expectations and suggestions by the person administering the treatment. Non-contact therapeutic touch and the placebo effect may be aspects of the same phenomena and could skew the results obtained (Jurgens, Meehan, \& Wilson, 1987).

\section{Significance of the Study}

Recent research is providing increasing evidence of the intimate relationship between the mind and body connection and supports the view of the body as an energy field which can be influenced by the environment and external techniques. In a scientific paradigmatic shift, a mechanistic or Newtonian view of the universe is being relinquished in favor of a more mindbody approach based on quantum physics. Becker $(1962 ; 1977)$ has demonstrated that direct current (DC) shifts measured on the skin lead to both tissue and bone growth as well as analgesia. Tiller (1982) found that the direct current over the peripheral body could be measured via the electrodermal response, and this pathway of electrical current has been found to correlate with acupuncture meridians. This DC current and the electrical field of the body are related perhaps through the glial cells. It is speculated that both our mind and our body simultaneously create a direct current, and a physical shift cannot occur without a mental shift (McCormack, 1991).

As a result of the growing evidence mounting from studies in 
psychoneuroimmunology, science is beginning to adapt a more mindbody concept which will provide support for practitioners to augment their treatment with holistic techniques. Non-contact therapeutic touch is considered a mindbody technique because it is non-invasive and addresses the body as a bioelectric energy field directly effecting the parasympathetic system. The parasympathetic system relates to and influences the immune system, which in turn plays a major role in healing and health.

The significance of this study will be its contribution to the developing body of knowledge on non-contact therapeutic touch, a modality which may induce a relaxation response. This would strengthen the empirical data that supports the use of non-contact therapeutic touch as an adjunct to occupational therapy. 


\section{CHAPTER 2}

\section{LITERATURE REVIEW}

The foundation of therapeutic touch as a medium for healing is based on the natural human potential to reach out with compassion and empathy. Since ancient times, this compassionate concern has been expressed crossculturally by the therapeutic use of hands (Kreiger, 1987). The founder of therapeutic touch, Dr. Dolores Krieger, maintains that the therapeutic use of hands and self is a universal human act and that from this human potential of man's ability to help man a practice in healing may be based.

Therapeutic touch was derived from the ancient healing practice known as the "laying-on-of-hands." It differs from the ancient practices in that it does not require a spiritual or religious commitment. The ancient practices were recorded in the hieroglyphics, cuneiform writings, and pictographs of the earliest literate cultures. However, it continues as it has been throughout the centuries as a little understood enigma of human intervention (Krieger, 1975).

The review of the literature covers the following specific areas: (a) the human body as an electromagnetic field, (b) early animal and plant studies, (c) physiological studies, (d) anxiety and stress studies, (e) pain studies, (f) human wound healing, and $(\mathrm{g})$ the Model of Human Occupation and Occupational Performance, the occupational therapy frame of reference related to this study.

The Human Body as an Electromagnetic Field

Critical to understanding the mechanisms proposed for the effects of 
therapeutic touch is the concept based in quantum physics of energy fields. Humans and the universe are composed of subatomic particles; physics examines the properties and interaction of these particles. The basic component of the universe is energy, not matter. This is expressed in Einstein's equation of $E=m c^{2}$ which indicates that mass and energy are interchangeable and are two manifestations of the same reality. Solid matter may be divided into smaller and smaller particles with the end result manifesting as pure energy. Thus, the practitioner and the client are ultimately two interacting energy fields. With therapeutic touch, the practitioner who gives the treatment focuses energy by centering or meditating, creating the intention to heal and directing more balanced energies to assist the client in regaining balance and pattern in his or her energy field (Payne, 1989).

Dr. Krieger's (1987) pioneering work postulated that therapeutic touch achieves its effectiveness by an interaction of energy fields between the practitioner and subject. Krieger said that the healing relationship is based on a transfer of life energy present in all living organisms. In health, this energy is flowing and abundant; in states of disease, it is blocked and depleted (Heidt, 1991).

Therapeutic touch is based on the assumption that a human being is not only a physical body but a complex interwoven pattern of energy. Disease is associated with a blockage, deficit, dysfunction, or disorder of this energy pattern. During the procedure of therapeutic touch, the practitioner enables the individual to release congestion and blockage in the energy field thus balancing the dysrhythmic area. The individual's innate healing ability is only enhanced by the practitioner. Implicit in the practice is the idea and assumption that within all living things is a drive toward growth, order, and wholeness (Harrison, 1990).

Several studies have shown evidence of the electromagnetic energy in the human energy field. The magnetic encephalograms sample the magnetic field 
produced largely by the ionic current flow of active cells. Zimmerman's (1989) work in the field of biomagnetism has defined the study of magnetic fields associated with life functions such as the brain and heart.

Edelberg's (1977) research has illustrated that microelectrode measurements indicate that the stratum corneum and other epidermal layers represent a significant pathway for ion conduction and that the transcutaneous potential is generated across a relatively thin layer of epidermal cells.

The research of Baker, Jaffe, \& Vanable (1982) has revealed voltage differences across various glabrous and gland-free regions of guinea pig skin. The voltages ranged from 30 to 100 millivolts across glabrous regions and from 0 to 10 millivolts across hairy regions of the skin. This illustrated that the glabrous regions of guinea pig skin have higher potential then across hairy regions. This study was significant for the electrode placement of the thermistor placed on the abdominal region for the current experiment.

In Western scientific research, the concept of the universal life energy is linked to field theory: all living organisms share a generalized life energy field (Jansch, 1980). Early research in field theory postulated that all living systems are vibrating fields of energy that send and receive from the surrounding universe (Margenau, 1962).

\section{Early Animal and Plant Studies}

Scientific documentation of the therapeutic touch process and its effects are still in its infancy. Well-known earlier examples of empirical research on therapeutic touch were performed by Bernard Grad, a psychologist at Montreal's McGill University. He has specialized in studying miraculous healers under scientific conditions. In one of his studies, a well-known healer placed his hands 
above and below a cage of mice for a period of 15 minutes twice a day. The mice were fed a diet deficient in iodine and were given chemicals which interfered with the absorption of iodine by the thyroid gland. The mice were divided into an experimental and a control group. Both groups developed goiters, the enlargement of the thyroid gland. However, the goiters of the group which the healer held his hands near grew significantly slower than those of the control group. Even without touching the mice, the healer's hands appeared to offer some protection against a physical disorder (Grad, 1965).

Grad (1965) devised a second experiment using mice with iodine deficiencies in which the healer held wool and cotton cuttings in his hands and placed them in the experimental group's cage. The control mice had cuttings that were not exposed to the healer. Again, the thyroid gland of the experimental group grew significantly slower than the control group. Grad concluded, "...the simplest explanation would seem to be that there is a life force emanating from the hands of people, probably more in some than in others."

One of the earlier examples of research on therapeutic touch (Grad, Cadoret, \& Paul, 1961) examined wound healing in mice. A surgical incision was performed on the backs of 300 mice and each wound was measured. The mice were randomly assigned to an experimental group treated by a healer, a control group treated by a medical student, or to a no-treatment group. On the 15th or 16th days of the study, the investigator found significantly smaller wound sizes for the mice treated by the healer. The mice in the no-treatment group showed better signs of healing than the ones treated by the medical student.

Another investigation by Grad (1965) studied the effect of therapeutic touch on the growth of barley seeds. The experimental group of seeds was watered daily with a $1 \%$ saline solution from an spen beaker held for 15 minutes by the healer. 
The control group received regular tap water. After 13 days, the experimental plants were taller and the number of plants per pot was greater.

Bush and Geist (1992) tested claims for psychic healing of living systems not amenable to suggestion. Suggestion may produce artifact in study results when there is failure to control for other possible explanations. The placebo effect and cognitive suggestion were both controlled in Bush and Geist's study. They found that some experimental methods in psychokinesis may produce electromagnetic field flux which would lead to erroneous conclusions. This study added electrical and magnetic controls to assess their effect which led to the conclusion that therapeutically touched corn seeds did not recover from saline injury significantly better than untreated controls.

\section{Physiological Studies}

Smith (1972) examined the potential effects of a healer and a magnetic field on the enzyme trypsin. The investigator used four solutions of the enzyme trypsin: (a) a control, (b) a solution exposed to ultraviolet light and treated by the healer, (c) a solution held by the healer, and (d) solution exposed to a magnetic field. No statistical tests of significance were reported. Yet Smith concluded that exposure to the healer and the magnetic field exerted similar effects, as these two solutions [(c) and (d)] displayed an increase in enzyme activity.

In another study, Krieger (1974) reported a significant increase in hemoglobin values in response to therapeutic touch (treatment group) versus routine hospital care (control group). However, this study was criticized for the absence of operational definitions, lack of random assignments to groups, and no control for the placebo effect.

Krieger, Peper, and Ancoli (1979) sought to identify physiologic responses of 
both the giver and the recipient during therapeutic touch. This study expanded on the previous research and conceptual and operational definitions of therapeutic touch were employed. The study found that the giver investigated exhibited a rapid synchronous beta activity on the EEG during the administration of therapeutic touch which was indicative of a state of deep concentration. In a study by Quinn (1988), results revealed that the receiver had a high level of alpha activity indicative of a state of deep relaxation. The recordings of the subject's brain waves, muscle tension, skin conductance, temperature, and heart rate all indicated that the subjects were relaxed. All of the subjects verbally confirmed the physiological data after the experiment was completed.

Randolph (1984) studied the physiologic responses of female college students to stressful stimuli. Randolph measured muscle tension, galvanic skin response, and temperature as measurements of anxiety after the intervention of therapeutic touch. This study was the first to use a double-blind design and to compensate for the placebo effect by employing a sham therapeutic touch intervention. There was no significant difference in the posttreatment measures of anxiety. These findings may be due to the fact that all other studies to date used therapeutic touch with a less-than-healthy population and the therapeutic touch intervention was given without the benefit of an assessment prior to treatment. A stress response was considered a natural physiologic phenomena to the stimuli in this study, and therapeutic touc! theoretically is not used to diminish the individual's essential ability to respond to threatening external stimuli (Quinn, 1988).

Post (1990) used a preexperimental, mixed factorial design to investigate whether therapeutic touch would significantly change muscle tone in 38 adult subjects. All subjects were lying supine in a quiet, darkened room with eyes closed in an inherently relaxed situation. The subjects experienced a significant decrease 
in muscle tone of the frontalis muscle during the span of intervention. Upon analysis no significant difference in muscle tone reduction was found between the two groups and results were inconclusive.

\section{Anxiety and Stress Studies}

Heidt (1991) found that patients who received one treatment of therapeutic touch experienced a significant decrease in state anxiety, but there was no significant decrease in trait anxiety following treatment. Heidt (1981) reported that among hospitalized cardiovascular patients, a therapeutic touch group had more significantly decreased levels of psychologic anxiety post treatment than did either of the other two groups. One of the groups received casual touch and the other received no touch. The patients' anxiety levels were measured on a standardized self-evaluation questionnaire before and after treatment. The results of both experiments were similar: the mean posttest anxiety scores of the therapeutic touch groups were significantly lower than those of the control groups. Yet it was impossible to determine if the anxiety reduction reported was due to an hypothesized transfer of energy or to the placebo effect. This investigation was influenced by the study by Krieger, et al (1979) which indicated that due to the increase in hemoglobin levels, therapeutic touch has the potential to elicit a state of physiologic relaxation.

Quinn (1984) replicated Heidt's study with several differences along with the premise that since therapeutic touch is an energy exchange, it will have the same effect with or without physical body contact on state anxiety (Quinn, 1984). Traditionally, therapeutic touch does not involve hand contact with the body. This specific research established hand and body contact over the cardiac and solar plexuses areas. Thus, the effect of therapeutic touch with contact and without 
contact on state anxiety appears to be virtually identical.

Fedoruk (1984) completed the first study of therapeutic touch conducted by a a person who was not a nurse and studied infants rather than adults. Fedoruk built the study on previous work examining the effects of therapeutic touch on anxiety and sought to answer the question: Does therapeutic touch reduce the stress of the nursing procedures and the taking of vital signs in premature infants in Neonatal, Intermediate and Intensive Care Units? The analysis indicated that there was a significant difference between infants treated with therapeutic touch and those who were treated with sham therapeutic touch or no therapeutic touch in decreasing arousal states to a more relaxed state during observation time. However, the study was criticized because the data presented did not make it possible to determine if the reported differences in infant state scores among the three treatment types was a function of the effectiveness of therapeutic touch in reducing arousal or the fact that sham therapeutic touch appears to have increased arousal. Another criticism of the study questioned the treatment times which were not equal; therapeutic touch lasted for 5 minutes and sham therapeutic touch lasted for 1 minute, and there was no control group. Finally, anxiety from the nurses may have been transferred to the infants during the sham therapeutic touch because of verbal operations and vocalizations of counting during the treatment intervention (Quinn, 1988).

Parkes (1985) studied the effects of therapeutic touch on the state anxiety of elderly hospitalized patients. Building on Quinn's work, Parkes used non-contact therapeutic touch and a sham therapeutic touch treatment. Comparison of posttest means using analysis of covariance (ANCOVA) revealed no statistically significant difference between groups. Findings of this study were consistent with the findings of Quinn (1982) who reported that a low but significant negative correlation was 
found between age anc change in anxiety scores. At issue was the validity of the index for anxiety used for the age group studied. Parkes (1985) reported that many of the subjects were concerned about trying to remember the answers from the prettest, which would seem to support this point (Quinn, 1988).

Kramer (1990) compared the effectiveness of therapeutic touch and casual touch for stress reduction of hospitalized children from 2 weeks to 2 years in age. Stress reduction was measured by pulse, peripheral skin temperature, and galvanic skin response (GSR) as observed on the GSR-II biofeedback instrument. The conclusion was that therapeutic touch significantly reduced the amount of time needed to calm children after stressful experiences.

\section{Pain Studies}

Connell and Meehan (1985) explored the effects of therapeutic touch on the experience of acute pain in postoperative patients. Connell and Meehan tested the hypothesis that there will be a greater decrease in posttest acute pain experience scores in subjects treated by therapeutic touch than in subjects treated by sham therapeutic touch. Their experimental design used multiple regression analysis with post-hoc comparison which indicated no significant difference between the two test groups. They suggested that a less conservative measure might be appropriate; that the 5-minute treatment time may not have been long enough for an analgesic effect. Additionally, standard medical treatment might have been too strong a medication by which to measure therapeutic touch (Quinn, 1988).

Keller and Bzdek (1986) examined the effects of non-contact therapeutic touch on tension headache pain and expanded upon the previous work which indicated that therapeutic touch decreased anxiety. Data analysis revealed a highly significant decrease in pain scores of subjects treated with therapeutic touch. Pain 
scores dropped an average of $70 \%$ in the therapeutic touch group and $37 \%$ in the placebo group. Keller's findings are consistent with the claims in the literature that therapeutic touch can relieve pain and supported Quinn's conclusion that physical contact during therapeutic touch is not necessary (Quinn, 1988).

\section{Human Wound Healing}

Wirth (1992) conducted a study demonstrating the potential for therapeutic touch in the healing of full thickness human dermal wounds. Results showed that subjects treated with therapeutic touch experienced a significant acceleration in the rate of wound healing as compared to non-treated subjects. Subjects were not informed of group assignment or the true nature of the active treatment modality in order to control placebo and expectation effects. Full thickness dermal wounds were incised on the lateral deltoid muscle using a skin biopsy instrument by a physician. Incisions were dressed and wound surfaces were measured on Days 0,8 , and 16 using a direct tracing method. Active and control treatments were comprised of daily sessions of 5-minute exposures to a hidden therapeutic touch practitioner or to sham exposure. The findings of this study concluded significant results and indicated that non-contact therapeutic touch may be an effective healing modality on full thickness human dermal wounds (Wirth, 1992).

\section{A Model of Human Occupation and Occupational Performance as Conceptual Frameworks}

Therapeutic touch reinforces the perspective of the physical body as only one aspect of the total being. In a broad concept of healing, therapeutic touch is based on the concept that withir the individual is an interaction of mind, body, and spirit resulting in a balance of energy flow. The effectiveness of the intervention 
can only be evaluated in relation to the total well being of the individual (Macrae, 1988). In relation to occupational therapy, the Model of Human Occupation views the human body as a composition of interrelated structures and functions organized into a coherent whole that interacts with the environment and is capable of maintaining and changing itself. The Model of Human Occupation with its integration of Open Systems Theory provides a framework for understanding not only the human being, but also larger systems (Padilla, 1992).

The Occupational Performance framework in occupational therapy addresses remediation of the performance areas of self-care, play/leisure, and work and the performance skill components of sensory-motor, psychosocial, and cognitive development. In occupational therapy, the area of performance subsystems which includes the constituents of skills encompasses the musculoskeletal system which needs to be sufficient to support performance of self-care, work, play and leisure. The primary concern is with the client's achievement of maximum independence in performance from the point of illness or injury through extended rehabilitation (Pedretti \& Pasquinelli, 1990).

McKehnie (1979) used the term "adjunctive" for methods which are added to and complement the primary methods and modalities used in occupational therapy treatment. Therapeutic touch would be labeled an adjunctive method used to enable purposeful activity. Adjunctive methods must be directed to the mastery of performance areas in occupational therapy practice. Exclusive use of adjunctive and enabling methods outside the context of the client's occupational performance would not be considered occupational therapy (Pedretti \& Pasquinelli, 1990). Therapeutic touch would be employed adjunctively to facilitate purposeful and functional activity. The crisis of a disability, chronic illness, anxiety, pain, or hopelessness are common problems of occupational therapy clients. These also can 
be conceived as imbalances in the client's energy field (Payne, 1989). From the energy perspective, when therapeutic touch is used as an adjunct to treatment, the individual is approached and treated as a whole system.

\section{Literature Summary}

Relevant research has been reviewed in the areas of electromagnetic energy, animal and plant studies; physiological responses, anxiety, stress, and pain studies; and human wound healing. All of the areas addressed share the component of therapeutic touch intervention and the findings were varied.

Keller and Bzdek (1986) summarized the findings on therapeutic touch as follows:

Therapeutic touch, a modern version of the laying-on-of-hands, was introduced into nursing by Krieger in 1975. It does not entail belief in the method or in any other concept on the part of its recipients to be effective (Krieger, 1987).

Therapeutic touch may or may not involve contact with the physical body, but contact is said always to be made with the energy field of the client (Krieger, 1975; Macrae, 1980; Quinn, 1982). It is reported by its practitioners to have three major effects: reduction of anxiety (Boguslawski, 1979; Heidt, 1981; Quinn, 1982); relief from pain (Krieger, 1979; Macrae, 1980); and a facilitation of the healing process (Boguslawski, 1979; Krieger, 1975). The studies on therapeutic touch are often criticized for poor methodology, lack of operational and conceptual definitions, and failure to employ a control group. Reports of clinically used therapeutic touch claimed results of decreased pain, decreased anxiety, health promotion, and acceleration of the natural healing process. Interaction in the energy fields between the practitioner and client during 
therapeutic touch intervention has been described. The theoretical application of therapeutic touch by the occupational therapist is guided by the model of Human Occupation and Occupational Performance framework. 


\section{CHAPTER 3}

\section{DESIGN AND METHODOLOGY}

\section{Research Question}

The research question proposed in this study was as follows:

Does the application of non-contact therapeutic touch influence the parasympathetic nervous system as evidenced by a relaxation response characterized by an increase in superficial skin temperature and a decrease in perceived level of stress when compared to a non-contact sham therapeutic touch group and a control group receiving no intervention?

\section{Research Design}

A three group pretest and posttest design was used in this preliminary pilot study. The independent variable is non-contact therapeutic touch. The dependent variables are perceived level of stress and superficial skin temperature.

The group design was as follows:

Group 1 - Non-contact therapeutic touch intervention - OOXOO

Group 2 - Non-contact sham therapeutic touch intervention - OOXOO

Group 3 - Control group with no direct intervention - OOOOO

Each group received two preintervention measures: one to measure the perceived level of stress based on a scale of 1 to 10 and a second to measure skin temperature for the first 4 minutes of baseline. The intervention was then administered for a time period of 6 minutes. The interventions were followed by 
the postintervention measures to determine the perceived level of stress on a scale of 1 to 10 and the superficial skin temperature from the 10 th to 14 th minute.

\section{Sample}

The subjects were student volunteers solicited from the Occupational Therapy Department of San Jose State University, San Jose, California. The subjects were presumed to be in good health and had no known muscular or neurological disorders. A total of $3 y$ subjects volunteered for the study. The sample included 7 males and 32 females. Subjects were randomly assigned into a non-contact therapeutic touch group, a non-contact sham therapeutic touch group, and a control group.

The subjects were asked not to engage in cognitive physiological control techniques such as meditation, yoga, breathing exercises, stress-management training, or self-hypnosis during the 15-minute testing period. Subjects were not aware of group assignment or to the true nature of the active treatment modality in order to control placebo and expectation effects. Subjects voluntarily agreed to participate in this study knowing that there were certain aspects of the experiment which would be explained to them at a later date in order not to bias the results.

\section{Procedure for Data Collection}

The study took place in the Central Classroom Building (CCB) Room 220 at San Jose State University, San Jose, California. The study was conducted on Monday mornings (9:00 a.m. to 12:30 p.m.), from October 26, 1992 to December 13, 1992. The subjects were scheduled for half-hour intervals and each one was seen individually during the assigned time period.

The assistant collecting the data was the primary investigator, Christine 
Tharnstrom, OTR. The intervention of non-contact therapeutic touch and non-contact sham therapeutic touch was administered by a trained practitioner in the application of therapeutic touch, Professor Guy L. McCormack. An Apple IIe computer printed the data collection for each subject in the form of a bar graph with the average skin temperature at 60 -second intervals for 15 minutes.

Upon entering the study room, the subject was asked to (a) sit down; (b) fill out a brief pretest descriptive questionnaire upon which he or she were also asked to rate his or her present level of stress on a scale of 1 to 10 with 10 being high and 1 being low (see Appendix A); (c) sign and date a consent form to participate in research at San Jose State University (see Appendix B); and (d) sign and date the Experimentai Subjects' Bill of Rights (see Appendix C). The subjects were given no information about the details of the procedure nor were they aware of the experimental design. The practitioner then read the following statement:

I am going to ask you to lie down in the supine position on this padded table for 15 minutes. You will be asked to wear these ear muffs to suppress auditory stimuli and this night mask to eliminate visual stimuli. A small thermistor or heat sensor will be taped to your abdomen. During the time you are lying on the table, we will be monitoring your skin temperature and will not come in physical contact with you. Please do not meditate or practice any self-regulation techniques during the time we are collecting our data. Do you have any questions?

The subject was then asked to lie down in the supine position on a padded massage table with hands at his or her sides and legs uncrossed. To eliminate extraneous variables of visual and auditory stimuli, each subject was asked to wear a sleeping mask and ear muffs. In this way, the investigation would control for the placebo effects. The Apple IIe computer, keyboard and printer were set up on a 
table next to the subject approximately 24 in. from the left side of his or her head. The thermistor sensory probe was on a $20 \mathrm{in}$. lead attached to the computer terminal. During the experiment the computer operation was displayed on the screen and no noise was audible. The bar graphics were printed out following the conclusion of the experiment with each subject.

The overhead lights were turned off, extraneous noise was minimized, and the mini blinds were closed to eliminate bright sunlight. Pillows were placed under the subject's head and knees for comfort. A temperature sensor was placed with non-porous paper tape 1 in. below the xyphoid process on the abdomen under the subject's shirt or blouse (see Figure 3). The temperature sensory probe measured skin temperature which was indicated in Fahrenheit degrees ( $\left.{ }^{\circ} \mathrm{F}\right)$ and observed in the Apple Ile computer monitor screen with the Biofeedback Microlab Human Relations Media Software program. The subject was asked to lie still for 15 minutes and told that he or she would be verbally cued to the termination of the study.

Only the investigator, practitioner, and subject were in the room. The other participants waited outside until their allotted time. During the experiment, there was no conversation. Only the sound of the air circulator in the room was consistently audible. The complete experiment lasted 15 minutes and an additional 15 minutes was allotted for subject orientation and recording of data. The same procedure was followed for each of the 39 subjects.

1. Non-contact therapeutic touch group: The practitioner stood beside the table with eyes closed. He centered himself with hands held together for 4 minutes. Centering is essential to this procedure. To center, the practitioner entered a relaxed state of mind to maintain an alpha or meditative state and focused on the intent to help or heal (Kreiger, 1987). The practitioner then 
assessed the subject's energy field by moving his hands 3 to $8 \mathrm{~cm}$ above the body moving in a head-to-toe direction (Wyatt, 1988). Following this long sweeping motion, the right hand was held $3-8 \mathrm{~cm}$. above the cardiac plexus and the left hand was held $3-8 \mathrm{~cm}$. above the mesenteric plexus for a period of 6 minutes. During this duration, the practitioner was focused on the intent to heal and imagined energy being drawn through his head from the environment and directed through his hands (Kreiger, 1987).

At the end of the 9th minute, the practitioner was physically cued by a tap on the hand from the primary investigator to terminate the therapeutic intervention. The practitioner then sat down on a chair directly behind him and remained silent. The skin temperature of the subject continued to be monitored by the computer for an additional 5 minutes with no intervention from the practitioner. This time was used to establish a postintervention skin temperature measurement.

2. Non-contact sham therapeutic touch group: This procedure followed Keller \& Bzdek's (1986) study to account for the placebo factor. The simulated procedure was indistinguishable from the experimental group in terms of physical motions. However, the intentionality component of the non-contact therapeutic touch process were omitted. The practitioner made no intent to help or heal; therefore, the element of intentionality was eliminated. Mental concentration on counting backwards from 200 became the focus, and eyes were kept open to attain a beta state without intentionality.

3. Control group: The initial procedure was exactly the same as for the previous groups, but the subject received no intervention. The sensory probe was attached to the abdomen; the subject was asked to lie still for 15 minutes in exactly the same manner as the other groups were instructed. The practitioner sat down in a chair beside the subject and remained silent. The subject was not aware of 
receiving no intervention because auditory and visual stimuli had been occluded.

When the designated time ended, the eye mask and ear muffs were removed, and the subject was asked to verbally answer the following posttest questions:

(a) On a scale of 1 to 10 , how would you rate your level of stress after the study?

(b) Did you see anything during the study? Yes/No (c) Did you hear anything during the study? Yes/No (d) Did you feel any hands come in contact with your body during the study? Yes/No (Appendix D).

The subject then left the room. The investigator recorded and printed out the data.

\section{Data Analysis}

The analysis of variance (ANOVA) was utilized to test whether or not the samples differed among the groups. The $\underline{F}$ distribution was the test statistic. The subject's skin temperature responses to the three interventions of (a) non-contact therapeutic touch, (b) non-contact sham therapeutic touch, and (c) control intervention were averaged for each of the time periods of (a) baseline, (b) intervention, and (c) postintervention and were subjected to ANOVA. The Apple IIe Biofeedback Human Relations Media software program computed average skin temperature at 60 -second intervals for a total of 15 skin temperature readings per subject over a 15-minute time period.

Demographic data on the subjects were described. Skin temperature reports were described by way of graphs. Stress level reports were described by way of subjective ratings on a scale of 1 to 10 .

Coefficients $(\underline{r})$ of variance for each subject were computed for skin temperature measures within each of the three time periods. Small coefficients indicate little or no variability (Mason, 1986). Correlations were calculated for 
pretest and posttest stress levels to determine the extent to which variation within these variables were similar (Oyster, Hanten, \& Llorens, 1987). The statistical analysis was performed with a standard computer program package, Statistical Package for Social Sciences (SPSS). 


\section{CHAPTER 4}

\section{DATA}

\section{Sample Characteristics}

A total of 39 subjects participated in the study. The sample consisted of 32 females (82.1\%) and 7 males (17.9\%). The age range was 21 to 47 years with a mean age of 27.72 years. Median weight was 138.56 pounds and median height was 5.49 feet. Thirteen subjects received non-contact therapeutic touch intervention, 13 subjects received a non-contact sham intervention, and 13 subjects received no touch intervention.

The following results were obtained from Questions 4 - 7 of the pretest questionnaire:

Question 4: Do you have any significant medical history or current problems?

Previous and current medical problems were experienced by $30.8 \%$ of the population and no medical problems were experienced by $69.2 \%$ of the population.

Question 5: Do you practice yoga on a reguiar basis for at least 30 minutes 3 times a week?

The practice of yoga 3 times a week was reported by $5.1 \%$ of the population and $94.6 \%$ of the population had no weekly yoga practice.

Question 6: Do you meditate on a regular basis for at least 30 minutes 3 times a week?

The practice of meditation 3 times a week was reported by $12.8 \%$ of the population and $87.2 \%$ of the population had no weekly meditation practice. 
Question 7: Are you familiar with the procedure and practice of therapeutic touch?

Two-thirds or $66.7 \%$ of the tested population were familiar with therapeutic touch and $33.3 \%$ were not familiar with the intervention.

The following results were obtained from Questions 2 - 4 of the posttest questionnaire:

Question 2: Did you see anything during the study?

Ninety-seven and four-tenths percent of the population did not see anything during the experiment and $2.6 \%$ said they could see light from under the mask or hands over their abdomen or chest area.

Question 3: Did you hear anything during the study?

Forty-eight and seven-tenths percent of the population did not hear anything during the experiment and $51.3 \%$ commented they could hear hands rubbing together, shuffling paper or the heater vent.

Question 4: Did you feel any hands on your body during the study?

One hundred percent of the population felt no hands come in contact with their body during the study.

\section{Individual Performance Across Three Time Periods}

An initial test of variance was used for each subject for each of the three time periods to determine if subjects were showing variability in their individual measures. Findings showed no variability occurred in any of the time periods (see Table 1). Time period averages were computed within each time period for each subject. Baseline coefficients of variance for Time 1 (CVT1) included skin temperature measures from baseline $(B)$ to the 4 th minute, intervention coefficients of variance for Time 2 (CVT2) included skin temperature measures from the 4 th 
Table 1

Coefficients of Variance Across Three Time Periods

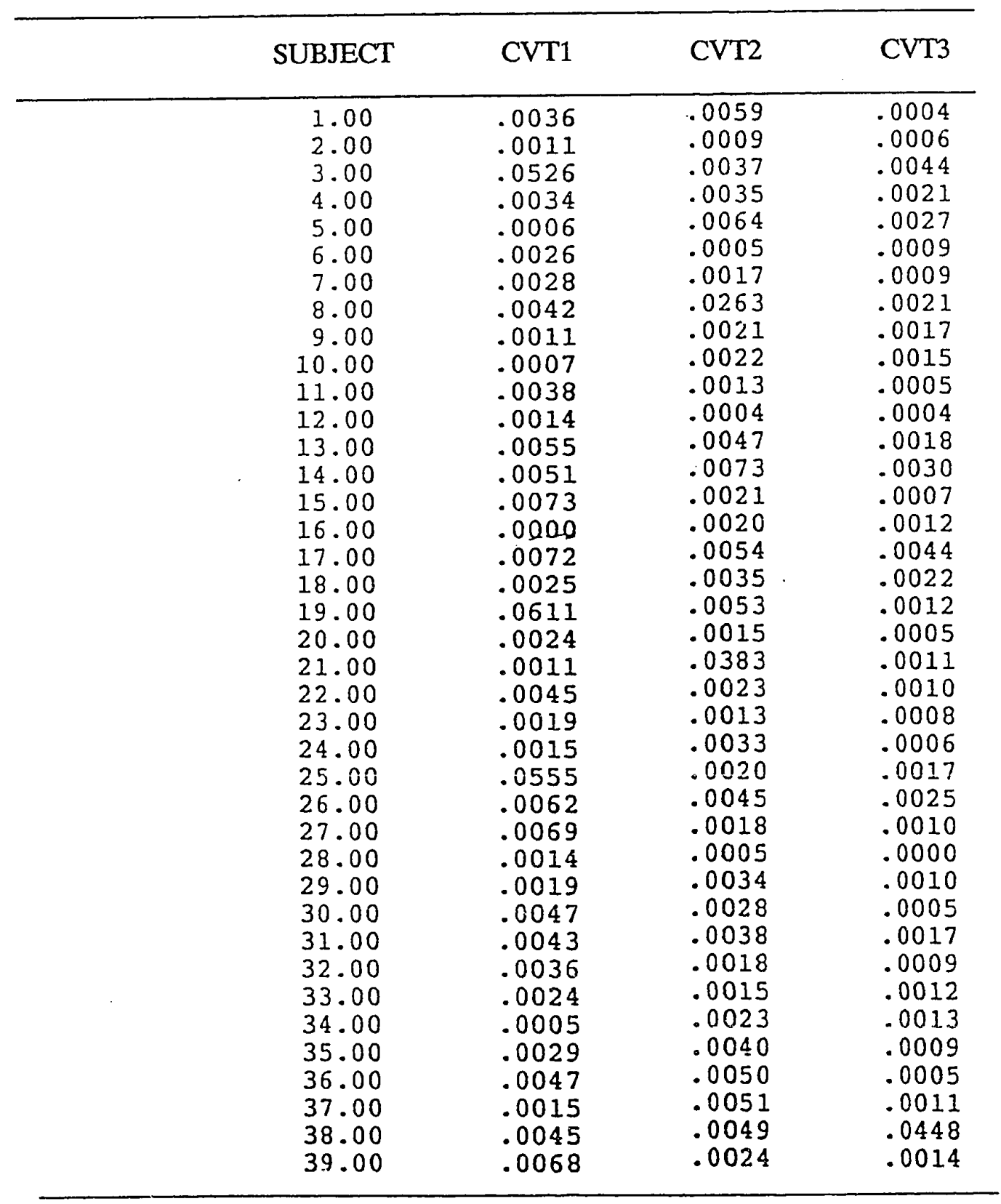

a CVT = Coefficient of variance (over) time 
minute to the 10th minute, and postintervention coefficients of variance for Time 3 (CVT3) included skin temperature measures from the 10th minute to the 14th minute. Coefficients of variance ranged from zero to less than one. Small coefficients indicated little or no variability in skin temperature measures. The coefficients were less than 1 for 39 subjects in all 3 averaged time periods. One subject showed 0 in the first time period only.

\section{Skin Temperature Data and Results}

The ANOVA statistics showed no significant difference among the three groups regarding skin temperature over the 15-minute time period (see Figure 4). The averaged skin temperature of all 13 subjects in each group over 15 minutes of time varied $.46^{\circ} \mathrm{F}$. The means of the three groups was not significantly different and the standard deviation varied between $2.98 \mathrm{oF}$ and $2.20 \mathrm{~F}$ with the therapeutic touch group showing the greatest standard deviation of $2.98 \mathrm{~F}$, the control group with $2.75 \mathrm{~F}$, and the sham group with the least amount of deviation at $2.20 \mathrm{~F}$. The mean for the therapeutic touch group was the least with $90.35^{\circ} \mathrm{F}$, the sham touch group was the highest mean with $90.85^{\circ} \mathrm{F}$, and the control group mean was $90.80^{\circ} \mathrm{F}$ (see Table 2).

In dividing the three interventions into three time periods with each time period averaged, the greatest deviation in temperature occurred in the therapeutic touch group at the baseline time period of baseline to the 4th minute with a standard deviation of $3.13 \mathrm{o}$. The lowest deviation was found in the sham group during the intervention period of the 4th minute to the 10th minute and the postintervention period. Both periods yielded the same deviation of $2.23 \mathrm{o}$. The highest mean temperatures were found during the postintervention period in the sham group at $91.49 \mathrm{~F}$. The lowest mean temperatures were produced during the 


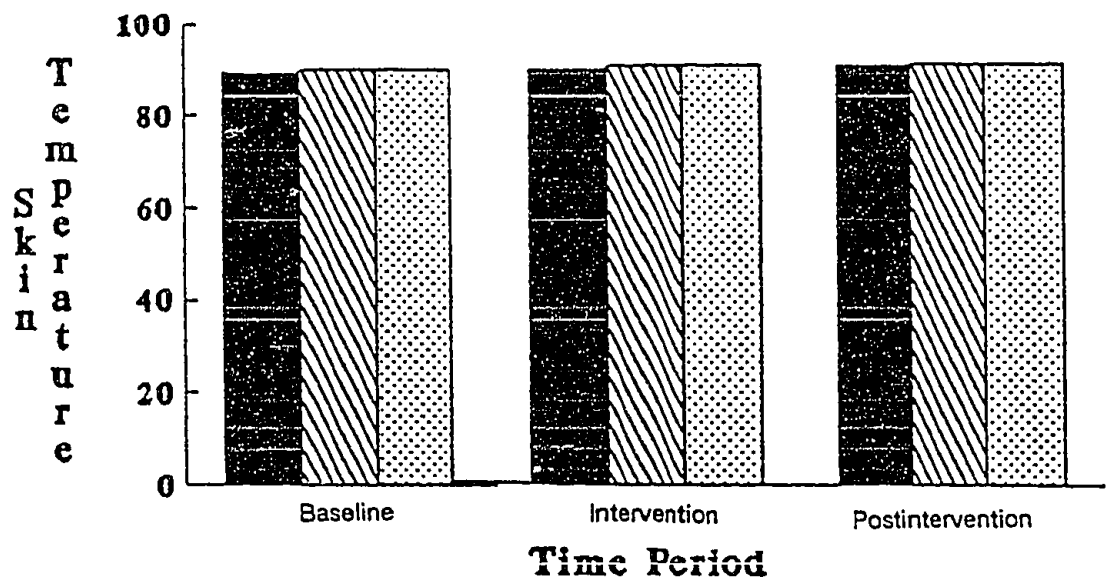

Non-contact Therapeutic Touch Group

Non-contact Sham Therapeutic Touch Group ER

Control Group

Figure 4. Bar Graph for Mean Skin Temperature Over Three Time Periods For Three Groups 
Table 2

Means and Standard Deviations of Skin Temperature for Three Groups

Over 15 Minutes.

\begin{tabular}{lccc}
\hline Group & Valid & Mean & $\begin{array}{l}\text { Standard } \\
\text { Deviation }\end{array}$ \\
\hline Non-contact Therapeutic Touch (TT) & 13 & $90.34{ }^{\circ} \mathrm{F}$ & $2.98{ }^{\circ} \mathrm{F}$ \\
Non-contact Sham Touch (ST) & 13 & $90.85{ }^{\circ} \mathrm{F}$ & $2.20{ }^{\circ} \mathrm{F}$ \\
Control (C) & 13 & $90.80 \circ \mathrm{F}$ & $2.75 \mathrm{oF}$ \\
\hline
\end{tabular}


baseline intervention in the therapeutic touch group at $89.51^{\circ} \mathrm{F}$ (see Table 3).

There is a 1.39 of difference among all three groups between the baseline period and postintervention period. The ANOVA found no significant difference among the groups (see Table 4).

All three groups showed a significant increase in skin temperature over a 15-minute time period while in the recumbent position, eyes closed, with the instruction to lie still (see Figure 5). The mean skin temperature increases over time in three individual groups were signifcant $\mathrm{F}(2.75)=40.55, \mathrm{p}<.005$ (see Figure 6).

The computer printout for each subject displayed the skin temperature range in a bar graph for a 15-minute time period. The baseline period with preintervention was " $\mathrm{B}$ " to the 4 th minute, the 4th minute to the 10 th minute was the intervention period, and the 10th minute to the 15 th minute was the postintervention period.

Included here are the therapeutic touch intervention subjects' bar graphs (see Figures 7 and 8) which show the skin temperature patterns for 5 of the 13 subjects. These five bar graphs were chosen because they show the most dramatic decrease in skin temperature; the other eight bar graphs did not show this event as distinctly. The graphics show that each of the five individuals experienced skin temperature increases during the intervention period and at minute 11 the skin temperature decreased when the practitioner's hands were removed. The decrease in temperature remains close to the 11 th minute reading throughout the postintervention period. This shows that vasodilation of the capiilary beds may have been stimulated by therapeutic touch intervention and that perhaps vasodilation was followed by vasoconstriction when the intervention ceased.

The non-contact sham therapeutic touch subjects' bar graphs (see Figure 9 
Table 3

Means and Standard Deviations (SD) of Skin Temperature for Three Groups Over

Three Averaged Time Periods

\begin{tabular}{|c|c|c|c|c|c|c|}
\hline & \multicolumn{2}{|c|}{$\begin{array}{l}\text { Non-contact } \\
\text { Therapeutic } \\
\text { Touch Group }\end{array}$} & \multicolumn{2}{|c|}{$\begin{array}{l}\text { Non-contact } \\
\text { Sham Therapeutic } \\
\text { Touch Group }\end{array}$} & \multicolumn{2}{|c|}{ Control Group } \\
\hline & Mean & $\mathrm{SD}$ & Mean & SD & Mean & $\mathrm{SD}$ \\
\hline Baseline & $89.51^{\circ} \mathrm{F}$ & $3.13^{\circ} \mathrm{F}$ & $90.05^{\circ} \mathrm{F}$ & $2.40^{\circ} \mathrm{F}$ & $90.11^{\circ} \mathrm{F}$ & $2.79^{\circ} \mathrm{F}$ \\
\hline Intervention & $90.52^{\circ} \mathrm{F}$ & $3.00^{\circ} \mathrm{F}$ & $90.99^{\circ} \mathrm{F}$ & $2.23^{\circ} \mathrm{F}$ & $90.95^{\circ} \mathrm{F}$ & $2.85^{\circ} \mathrm{F}$ \\
\hline Postintervention & $90.99^{\circ} \mathrm{F}$ & $2.95^{\circ} \mathrm{F}$ & $91.49^{\circ} \mathrm{F}$ & $2.23^{\circ} \mathrm{F}$ & $91.35^{\circ} \mathrm{F}$ & $2.75^{\circ} \mathrm{F}$ \\
\hline
\end{tabular}


Table 4

Means and Standard Deviations of Skin Temperature Averaged in All Three

Groups Over Three Time Periods

\begin{tabular}{lccc}
\hline & Valid $N$ & Mean & $\begin{array}{l}\text { Standard } \\
\text { Deviation }\end{array}$ \\
\hline Baseline Average & 39 & 89.89 of & 2.73 o F \\
Intervention Average & 39 & 90.82 oF & 2.65 oF \\
Postintervention Average & 39 & 91.28 of & 2.60 oF \\
\hline
\end{tabular}




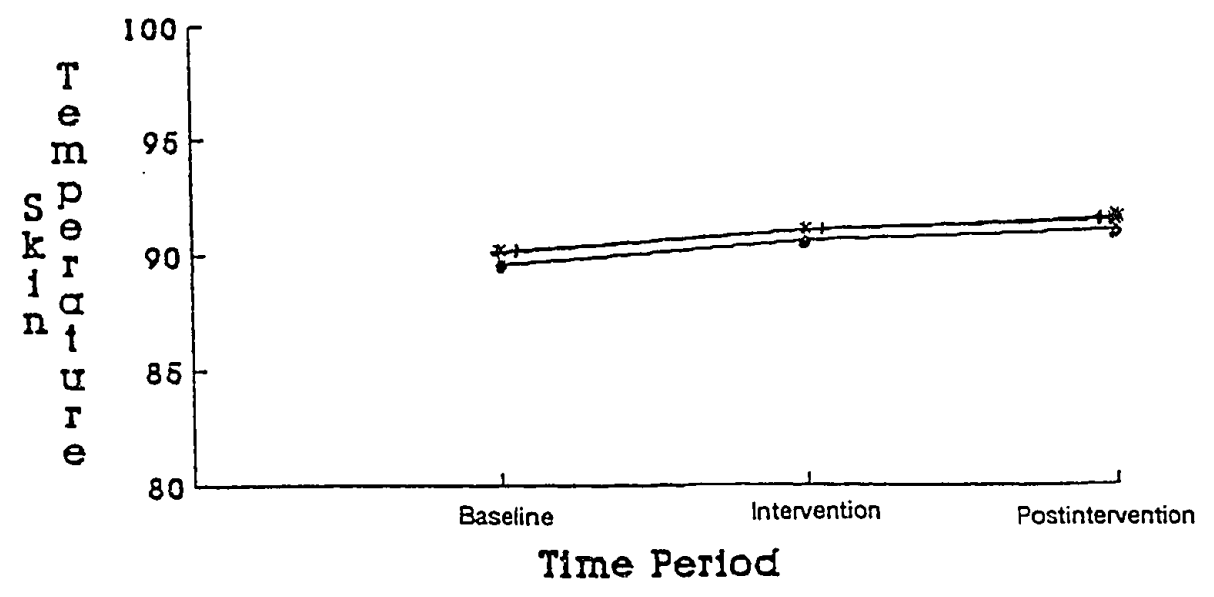

Non-contact Therapeutic Touch Group
Non-contact Sham Therapeutic Touch Group
Control Group

Figure 5. Skin Temperature Increases Over Three Time Periods in Three Groups 


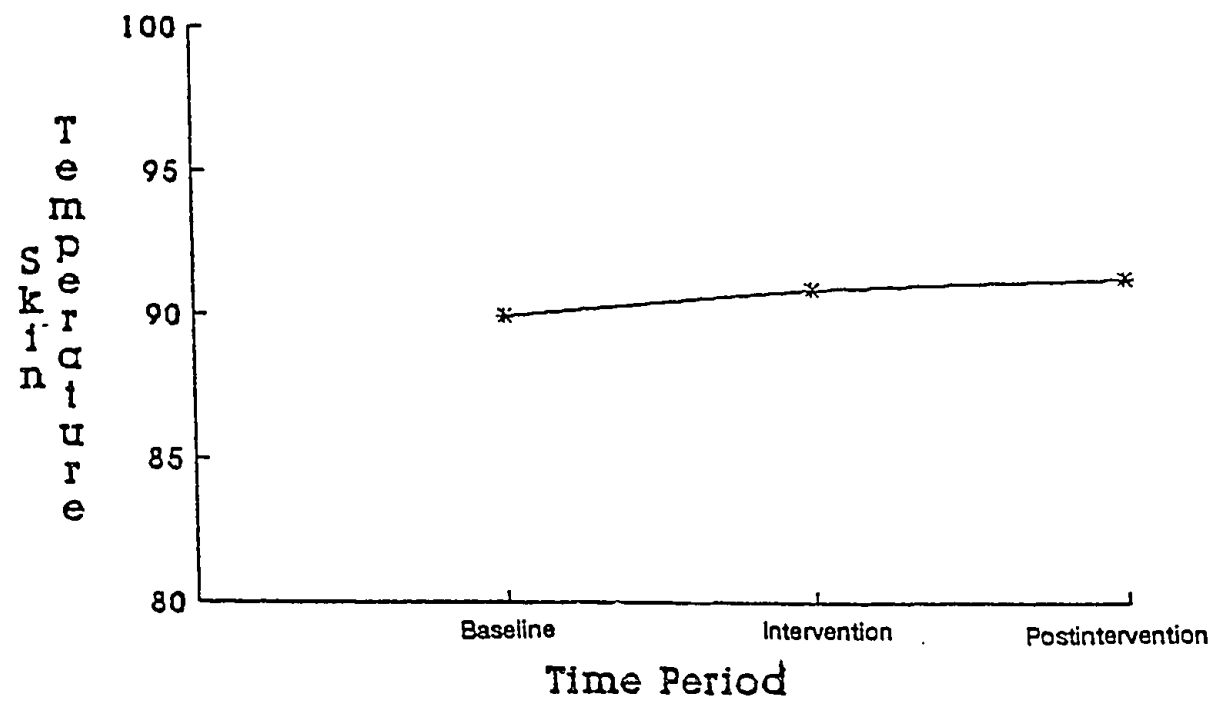

Figure 6. Mean Skin Temperature Increases Over Time in Three Groups $\mathrm{F}(2.72)=40.55, \mathrm{p}<.005$ 


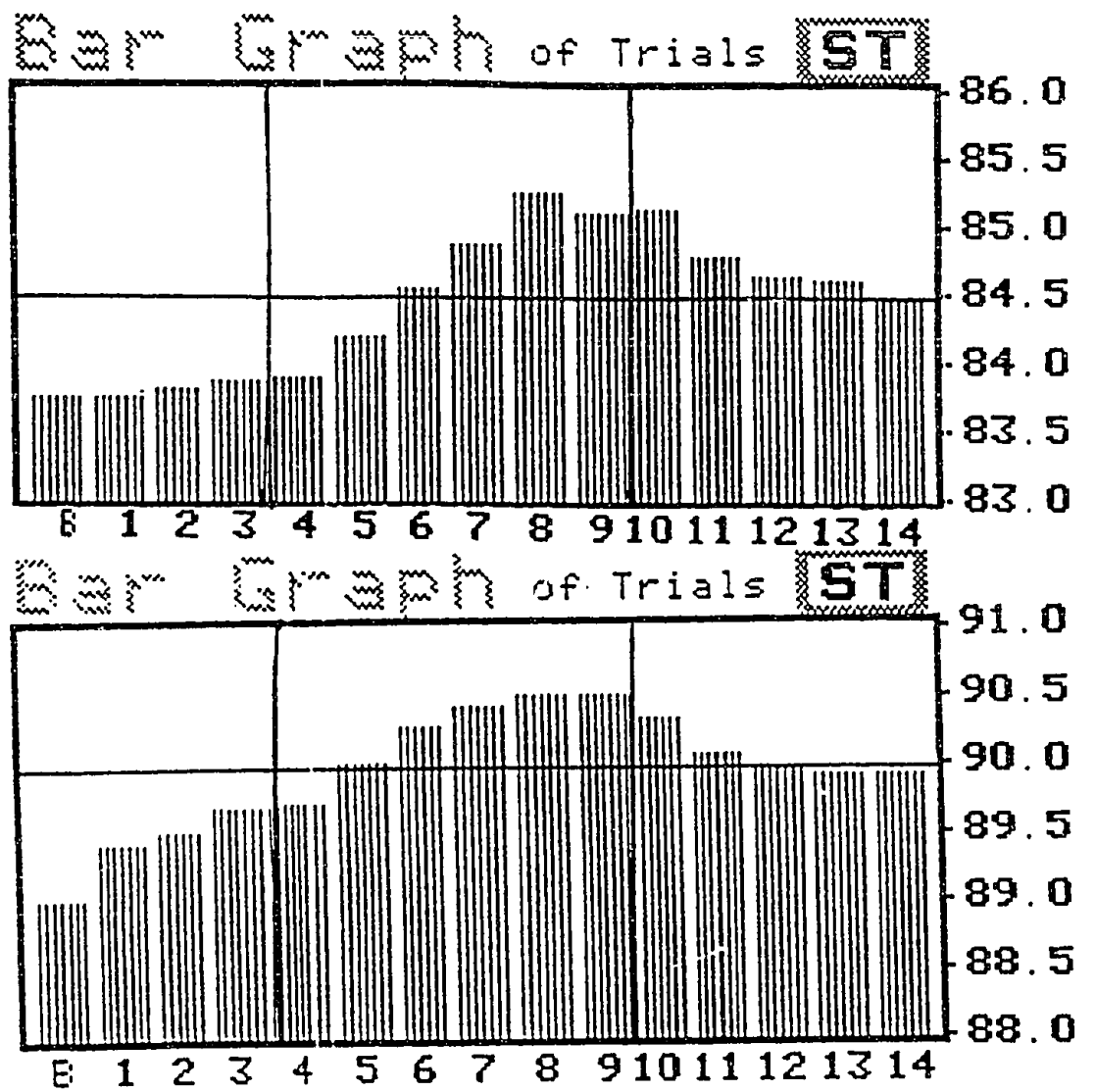

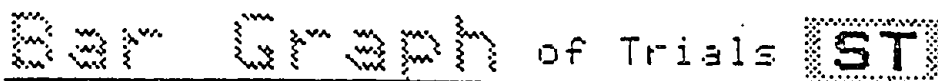

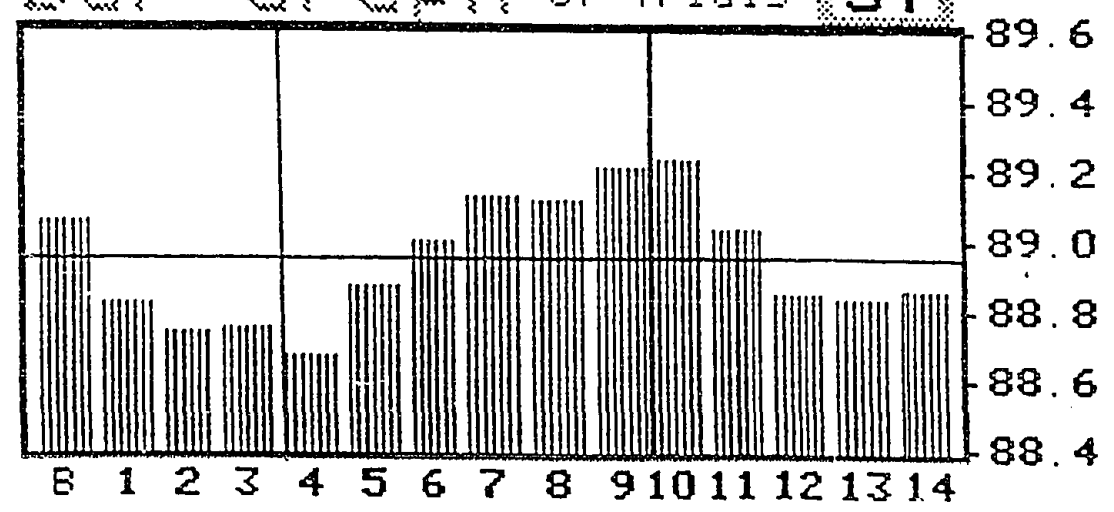

Trial [uration = 60 serarids

Figure 7. Bar Graphs for Three Non-contact Therapeutic Touch Subjects 


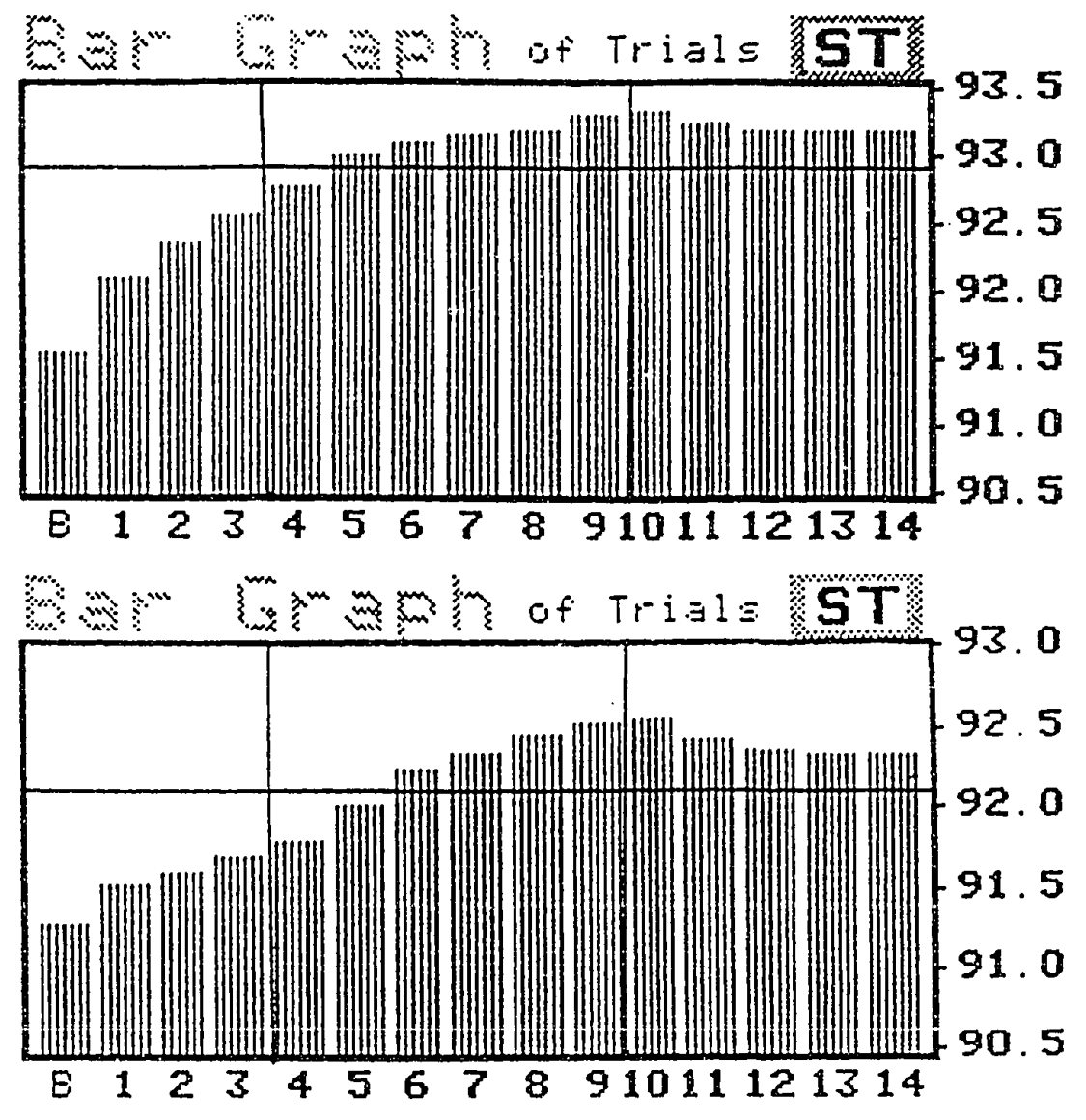

Trial [uration = 60 seconds

Figure 8. Bar Graphs for Two Non-contact Therapeutic Touch Subjects 


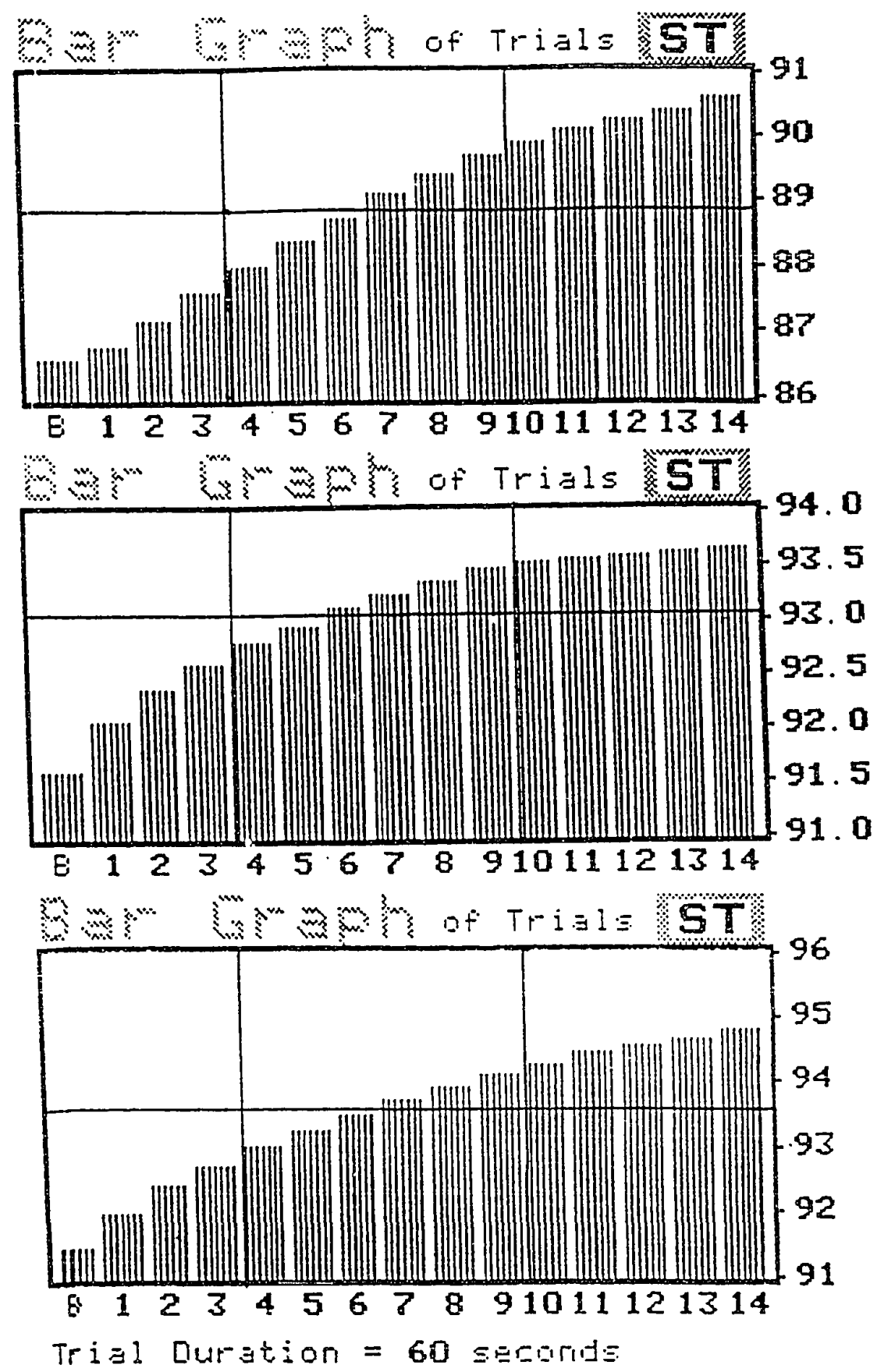

Figure 9. Bar Graphs for Three Non-contact Sham Therapeutic Touch Subjects 
and 10) and the control subjects' bar graphs (see Figure 11 and 12) appear to be almost identical. Following the non-contact sham intervention or no intervention, the skin temperature either remained steady or continued to rise slightly. No drop in skin temperature is evident from these bar graphs.

It appears that skin temperature will increase secondary to vasodilation of the capillary beds if a subject is asked to lie down and be still with occluded visual and auditory stimulus for a 15 -minute time period. With the variable of intentionality being the determining factor between the non-contact therapeutic touch group and the non-contact sham therapeutic touch group, it appears graphically as if the withdrawal of intentionality affects vasoconstriction of the capillary beds in 5 of the 13 non-contact therapeutic touch subjects' bar graphs. However, statistical analysis yielded no significant differences in skin temperature changes over time among the three groups. The drop in temperature experienced by the non-contact therapeutic touch group may have been due to chance. In this study, vasoconstriction coincided with the removal of intentionality.

\section{Perceived Stress Level Data and Results}

On a subjective stress scale of 1 to 10 with 1 being low and 10 being high, $27.2 \%$ of the participants reported pretest stress levels of less than 5 prior to intervention, $71.9 \%$ of the participants reported pretest stress levels more than 5 prior to intervention. In no case did a subject report a stress level of 1 or 2 .

Following the allotted 15-minute experiment, subjective posttest stress levels were reported by $87.2 \%$ of the participanis at less than 5 and $12.8 \%$ reported posttest stress levels of 6 or 7; 15.4\% reported a posttest stress level of 1 and 35.9\% reported a posttest stress level of 2 (see Table 5). The reported pretest stress mean was 7 and the reported posttest stress mean was 3 with a standard deviation of 2 

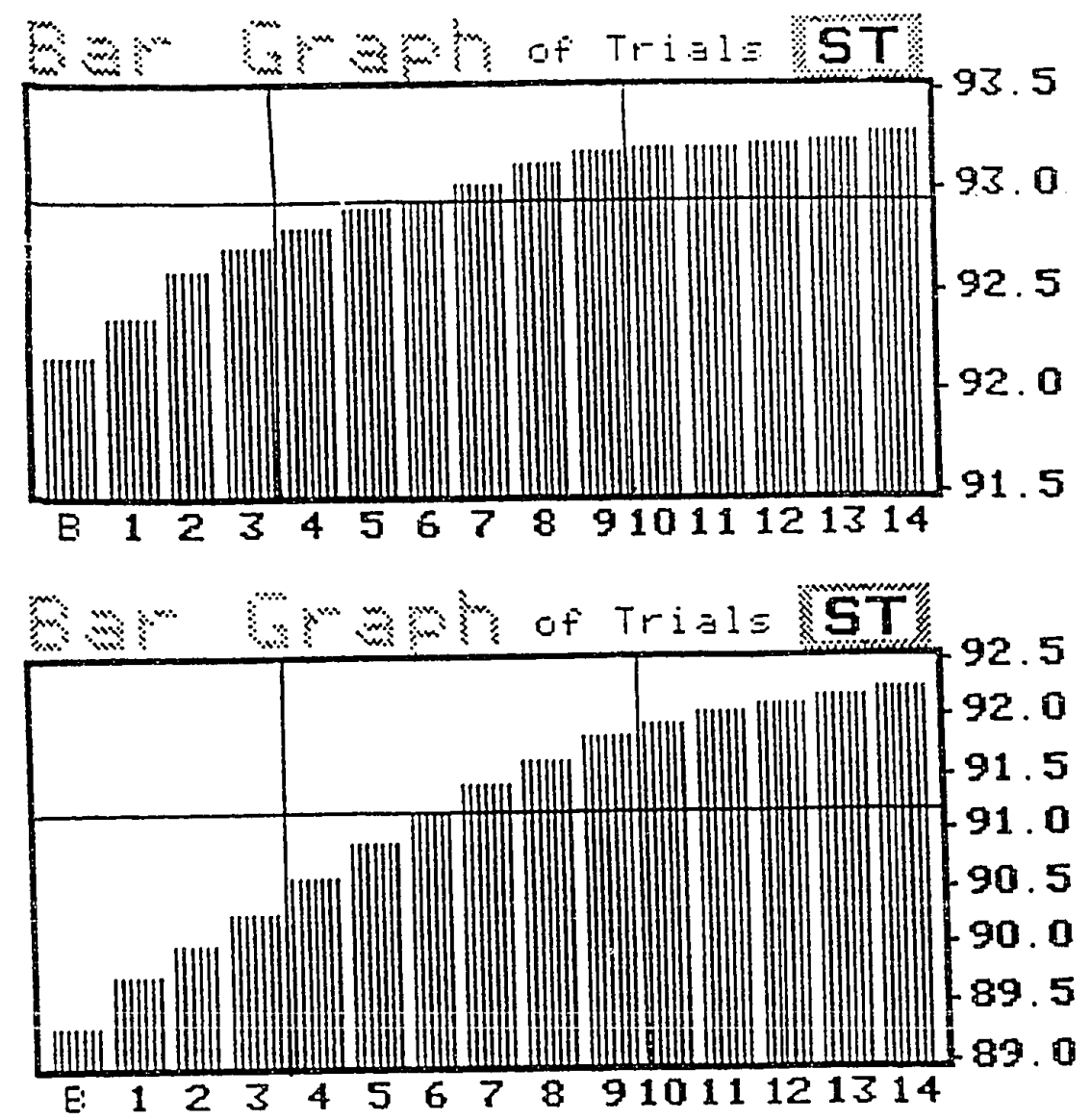

Trial [lurgtian = 60 seconds

Figure 10. Bar Graphs for Two Non-contact Sham Therapeutic Touch Subjects 


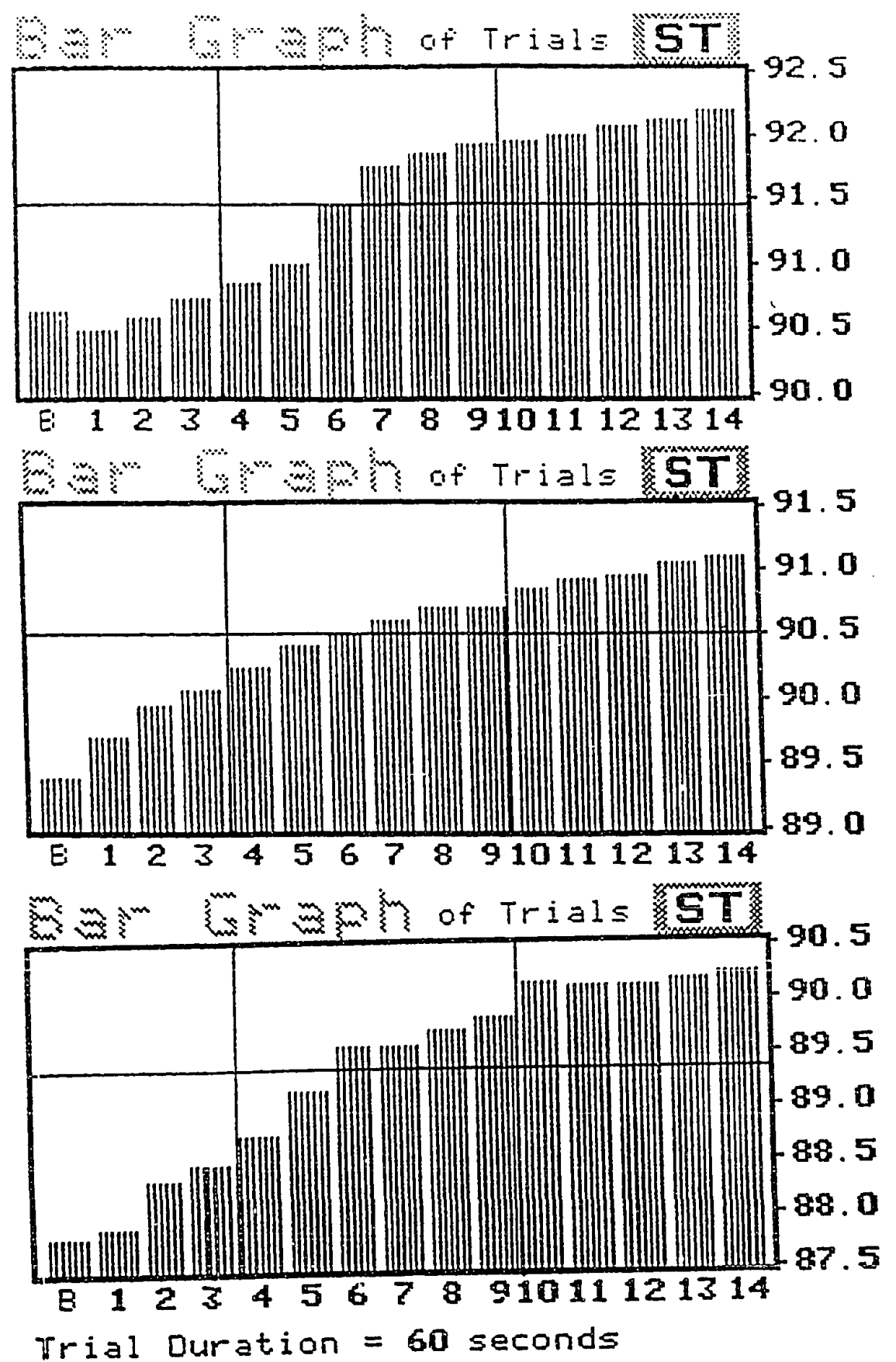

Figure 11. Bar Graphs for Three Control Subjects 


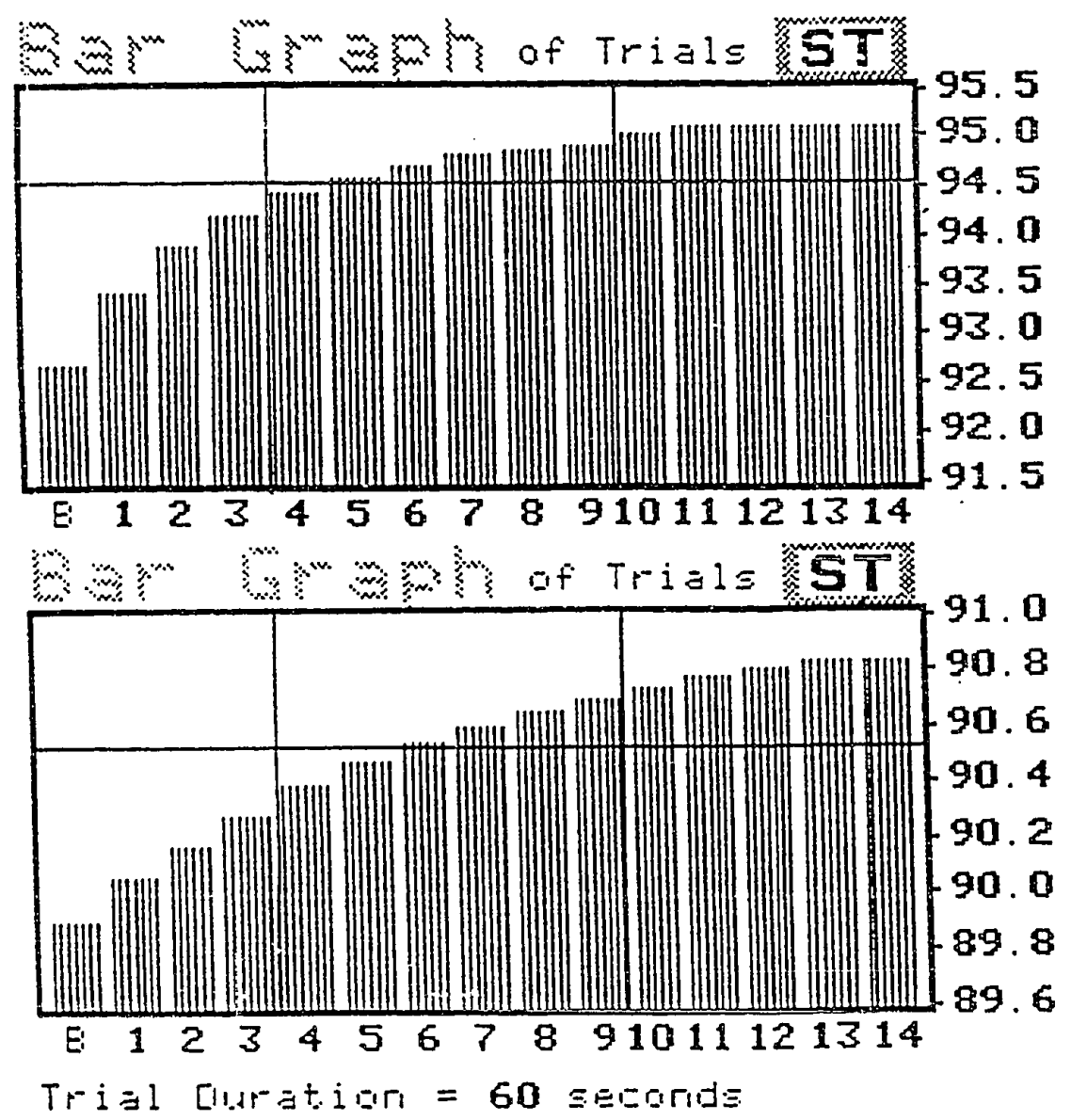

Figure 12. Bar Graphs for Two Control Subjects 
Table 5

Pretest and Posttest Stress Level Ratings

\begin{tabular}{|c|c|c|}
\hline & Frequencies & Percentages \\
\hline \multicolumn{3}{|c|}{ Pretest Stress Level Ratings } \\
\hline 3 & 1 & $2.6 \%$ \\
\hline 4 & 5 & $12.8 \%$ \\
\hline 5 & 5 & $12.8 \%$ \\
\hline 6 & 4 & $10.3 \%$ \\
\hline 7 & 6 & $15.4 \%$ \\
\hline 8 & 11 & $28.2 \%$ \\
\hline 9 & 3 & $7.7 \%$ \\
\hline 10 & 4 & $10.3 \%$ \\
\hline \multicolumn{3}{|c|}{ Posttest Stress Level Ratings } \\
\hline 1 & 6 & $15.4 \%$ \\
\hline 2 & 14 & $35.9 \%$ \\
\hline 3 & 6 & $15.4 \%$ \\
\hline 4 & 3 & $7.7 \%$ \\
\hline 5 & 5 & $12.8 \%$ \\
\hline 6 & 2 & $5.1 \%$ \\
\hline 7 & 3 & $7.7 \%$ \\
\hline
\end{tabular}


(see Table 6).

A correlation was computed for pretest and posttest stress levels and a positive correlation was found $(\underline{r}=.48, \underline{p}=.002)$.

\section{Research Question Findings}

The research question was as follows: Does the application of non-contact therapeutic touch influence the parasympathetic nervous system as evidenced by a relaxation response characterized by an increase in superficial skin temperature and a decrease in perceived level of stress when compared to a non-contact sham therapeutic touch group and a control group receiving no intervention? No significant difference was found among the three groups for skin temperature (see Table 2 and Figure 4). All three groups showed an increase in skin temperature. A decrease in perceived level of stress was evident in all groups (see Table 6).

\section{Summary}

Present findings suggested that skin temperature increase significantly in all three groups regardless of type of intervention. No significant differences were found among the three groups and no interaction was found among the three groups in time. All subjects showed a decrease in stress levels and a correlation was found between the subjects with high and low stress levels. Subjects with high stress decreased their stress level; however, it continued to remain high. Subjects with low stress lowered their stress level even lower on a subjective stress calculation. A coefficient of variance was computed and revealed that all subjects reacted in a similar manner in relation to skin temperature. There were no extreme highs or lows in skin temperature ranges over time. 
Table 6

Pretest and Posttest Stress Means and Standard Deviations

\begin{tabular}{lccc}
\hline & Valid $N$ & Mean & $\begin{array}{c}\text { Standard } \\
\text { Deviation }\end{array}$ \\
\hline Pretest Stress Level Ratings & 39 & 7 & 2 \\
Posttest Stress Level Ratings & 39 & 3 & 2 \\
\hline
\end{tabular}




\section{CHAPTER 5}

\section{DISCUSSION OF RESULTS WITH IMPLICATIONS FOR THE PROFESSION}

\section{Discussion of Results}

This investigation was a preliminary pilot study with a small sample and the intent of measuring the effects of non-contact therapeutic touch on the parasympathetic nervous system as evidenced by a relaxation response. The study showed that with only 4 minutes of relaxation the cutaneous capillary beds react with vasodilation and continue to dilate and raise skin temperature over a period of 15 minutes. The non-contact therapeutic intervention did not seem to influence the response to a statistically significant degree. However, graphically there is evidence that intention has a measurable effect. In 5 of the 13 bar graphs for the non-contact therapeutic touch group there was a decrease in skin temperature at the 10th minute when the hands were withdrawn from over the cardiac and mesenteric plexuses; however, this may have been due to chance.

In a relaxed supine position with eyes closed for 15 minutes, vasodilation of the capillary beds is evident; thus increasing blood flow and eliciting a relaxation response as related to an elevation in skin temperature and a decrease in stress

level. Intentionality appears to coincide with a decrease in skin temperature following the withdrawal of the hands over the cardiac and mesenteric plexses after the 10th minute in the non-contact therapeutic touch group as illustrated in Figures 7 and 8. All subjects showed a decrease in stress; however, it cannot be determined if the non-contact therapeutic touch group showed more of a stress reduction in 
comparison to the other two groups because of the small sample size. All groups showed an increase in skin temperature and demonstrated a significant decrease in reported stress level.

It appears distinctive in the five therapeutic touch bar graphs that an effect portrayed itself at the 10 th minute resulting in a decrease in skin temperature. This could be a speculative measure of intentionality in the interaction between the practitioner and subject. Margenau (1962) postulated that all living systems are vibrating fields of energy, sending information to and receiving from the universe that surrounds them. It appears that intentionality creates a measurable energy and when the focus is withdrawn, there is a physiological reaction in the body displayed as a change in skin temperature which indicates an influence on the parasympathetic nervous system.

\section{Implications for the Profession of Occupational Therapy}

Practitioners and researchers differ in their explanation of what actually happens during the therapeutic touch process, but all agree that the experience is important for leaving the patient with a greater sense of comfort and relaxation (Krieger, 1987). Therapeutic touch offers a framework in which the power of human interaction may be considered as a resource in healing. Health care needs to become more mindful of the effect of human interaction and less dependent on drugs and technology.

This study was designed with the intent of identifying non-contact therapeutic touch as a definitive adjunctive modality to use with clients in occupational therapy practice. In more than one moderately well-designed study, therapeutic touch has been found to be successful in decreasing pain, decreasing anxiety and stimulating human wound healing; it has also been used in the newborn intensive care settings 
with infants. From this study, it appears that just the closeness of a practitioner, the supine position, eyes closed and the suggestion to lie still will increase skin temperature and decrease state stress, thus, inducing a relaxation response. Perhaps simply being relaxed with a decrease in state stress would make a patient more open to various therapeutic modalities and increase the therapeutic effect of purposeful activities.

\section{Recommendations for Further Study}

Recommendations for further research in the field of therapeutic touch include the following:

1. Use of a case study design would offer a more in-depth analysis of the effects of therapeutic touch on an individual basis.

2. An increase in sample size with more than 30 subjects in each group which would provide a greater probability factor and chance for significant differences among groups in regard to skin temperature.

3. Subjects should be screened for medical problems prior to assignment to groups.

4. Use of experimental design could incorporate a cognitive component and an autogenic suggestion component to determine if prior knowledge of therapeutic touch would have an effect on skin temperature and stress level. To thoroughly inform subjects of the treatment modality could influence them cognitively to possibly increase the effect of therapeutic touch.

5. A study should be initiated that is designed to perform therapeutic touch on a population with high muscle tone and use the Apple Ile Biofeedback lab program to measure muscle tone, which is also an indicator of relaxation.

6. A quasi-experimental design should be used over a longer period of time 
to observe when the skin temperature will begin to drop, measuring differences in the three groups in their ability to sustain a higher temperature for a longer period of time. The goal of such a study might be to determine when skin temperature will begin to drop and the time period needed to illustrate a difference among the three groups.

7. A study should be initiated that is designed to irvestigate the correlation between group intervention and stress reduction. The question posed would be whether the non-contact therapeutic touch group experience a greater decrease in stress levels than a sham or control group?

8. A sick population should be used to study the physiological responses in a three group comparison of non-contact therapeutic touch, non-contact sham therapeutic touch, and a control group.

Further research in the area of therapeutic touch is recommended to validate therapeutic touch scientifically and to explore the mindbody connection in relation to therapeutic intervention in the field of occupational therapy. 


\section{REFERENCES}

Baker, A., Jaffe, L., \& Vanable, J. (1982). The glabrous epidermis of cavies contains a powerful battery. American Physiological Society, 242, 360-365.

Becker, R. O. (1962). The direct current control system: A link between environment and organism. New York State Journal of Medicine, 40, 1169-1176.

Becker, R. O. (1977). An application of direct current neural systems to psychic phenomena. Psychogentic Systems, 2, 189-196.

Becker, R. O., \& Selden, A. (1985). The body electric: Electromagnetism and the foundation of life. New York: William Morrow.

Benson, H. (1975). The relaxation response. New York: William Morrow.

Boguslawski, M. (1979). The use of therapeutic touch in nursing. Journal of Continuing Education in Nursing, 10(4), 9-15.

Bush, A., \& Geist, C. (1992). Testing electromagnetic explanations for a possible psychokinetic effect of therapeutic touch on germinating corn seed. Psychological Report, 70, 891-896.

Connell, M., \& Meehan, M. (1985). The effect of therapeutic touch on the experience of acute pain in post-operative patients. Disseration Abstracts International, 46, 795B. (University Microfilm No. DA8510765).

Edelberg, C. (1977). Relation of electrical properties of skin to structure and physiologic state. The Journal of Investigative Dermatology, 69, 324-327.

Fedoruk, R. (1984). Transfer of the relaxation response: Therapeutic touch as a method for reduction of stress in premature neonates. Dissertation Abstracts International, $46,978 \mathrm{~B}$.

Glueck, B. C., \& Stroebel, C. F. (1975). Biofeedback and mediation in the 
treatment of psychiatric illness. Comprehensive Psychiatry, 16, 309.

Grad, B., Cadoret, R., \& Paul G. (1961). The influences of an unorthodox method of treatment on wound healing in mice. International Journal of Parapsychology, 3 (7), 5-24.

Grad, B. (1965). Some biological effects on the laying-on-of-hands: A review of experiments on animals and plants. Journal of the American Society for Physical Research, 59, 95-127.

Guyton, A. (1991). Textbook of medical physiology (8th ed). Philadelphia: Saunders.

Harrison, E. A., Weiner, J. S., Tanner, J. M., Bainicott, N. A., \& Reynolds, V. (1983). Human Biology: An introduction to human evolution, variation, growth \& ecology (2nd ed). London: Oxford University Press.

Harrison, M. J. (1990). Therapeutic touch. New Zealand Nursing Journal, $\underline{83}(4)$, 23-24.

Heidt, P. (1981). Effect of therapeutic touch on anxiety level of hospitalized patients. Nursing Research, 30 (1), 32-27.

Heidt, P. (1991). Helping patients to rest: Clinical studies in therapeutic touch. Holistic Nursing Practice, 5(4), 57-66.

Jansch, E. (1980). The self-organizing universe: Scientific and human implications of the emerging paradigm of evolution. Oxford: Peergamon Press.

Jurgens, A., Meehan, T., \& Wilson, 4. (1987). Therapeutic touch as a nursing intervention. Holistic Nursing Practice, 2(1), 1-13.

Kandle, E., \& Schwartz, J. (1985). Principles of neural science (2nd ed.). New York: Elsevier.

Karabelher, P., Bhole, M., \& Gharste, M. (1979). Muscle activity in some asanas. Yoga Mimamsa, 12(5), 24-29. 
Keller, E., \& Bzdek, V. (1986). Effects of therapeutic touch on tension headache pain. Nursing Research, $\underline{35}(2), 101-106$.

Kramer, N. (1990). Comparison of therapeutic touch and casual touch in stress reduction of hospitalized children. Pediatric Nursing, 16, 483-485.

Krieger, D. (1974). Healing by the "laying-on" of hands as a facilitator of bioenergetic change: The response of in-vivo humans hemoglobin. International Journal of Psychoenergetics Systems, 1, 121-129.

Krieger, D. (1975). Therapeutic touch: The imprimateur of nursing. American Journal of Nursing, 75, 784-787.

Krieger, D., Peper, E., \& Ancoli, S. (1979). Therapeutic touch: Searching for evidence of physiological change. American Journal of Nursing, 79, 660-662.

Krieger, D. (1987). Living the therapeutic touch: Healing as a life style. New York: Dodd Mead.

Maciae, J. (1980). Therapeutic touch in practice. In J. Jackson (Ed.), The Whole Nursing Catalog, (pp. 546-549). Philadelphia: Saunders.

Macrae, J. (1988). Therapeutic Touch: A Practical Guide. New York: Alfred A. Knopf.

Margenau, H. (1962). Fields in physics and biology. Main Currents in Modern Thought, 19(9), 11-12.

Mason, R. (1986). Statistical Technique in Business and Economics (6th ed). Homewood, IL: Irwin.

McCormack, G. (1991). Therapeutic use of touch for the health professional. Tucson, AZ: Therapy Skill Builders.

McCormack, G. (1992). The therapeutic benefit of the relaxation response. Occupational Therapy Practice, 4(1), 51-60.

McDonagh, J.. \& Eugene, T. (1972). Transcendental meditation technique and 
temperature homeostasis. Scientific research on the transcendental meditation program: Collected paper, 1(31), 261.

McKenhie, J. L. (1979). Webster's new universal unabridged dictionary. New York: Dorset \& Baber.

Miehler, B., Miller, L., Antonucci, P., \& Cochran, P. (1986). Biofeedback microlab guide [computer program manual]. Pleasantville, NY: Human Relations Media Software.

Miller, B., \& Keane, C. (1987). Encyclopedia and dictionary of medicine, nursing, and allied health (4th ed.). Philadelphia: Saunders.

Newshaw, G. (1989). Therapeutic touch for system control in persons with aids. Holistic Nursing Practice, 3 (4), 45-51.

Oyster, C., Hanten, W., Llorens, L. (1987). Introduction to Research. A Guide for the Health Science Professional. New York: Lippincott.

Padilla, R. (1992, October). The Model of Human Occupation. Presentation at the Occupational Therapy Association of California Conference, Stanford, CA.

Parkes, B. (1985). Therapeutic touch as an intervention to reduce anxiety in elderly, hospitalized patients. Disseration Abstracts International, 47, 573B.

Payne, M. (1989). The use of therapeutic touch with rehabilitation clients. Rehabilitation Nursing, 14(2), 69-72.

Pedretti, L., \& Pasquinelli, S. (1990). A frame of reference for occupational therapy in physical dysfunction. In L. Pedretti \& B. Zoltan (Eds), Occupational therapy--practice skills for physical dysfunction, (pp.1-17). St. Louis: Mosey.

Peper, F. \& Pollini, S. (1976). Fast beta activity recording: Limitations, problems, and subjective reports. Presentation at the Biofeedback Research Society, Colorado Springs, CO.

Post, N. (1990). The effects of therapeutic touch on muscle tone. (Masters thesis, 
San Jose State University, California, 1990). Masters Abstract International, 28(4), 587.

Quinn, J. (1982). An investigation for the effect of therapeutic touch done without physical contact on state anxiety of hospitalized cardiovascular patients.

Dissertation Abstracts International, 43, 1797B. (University Microfilm No. DA 8226788)

Quinn, J. (1984). Therapeutic touch as energy exchange: Testing the theory. Advances in Nursing Science, 6(1), 42-49.

Quinn, J. (1988). Building a body of knowledge: Research on therapeutic touch 1974-1986. Journal of Holistic Nursing, 6(1), 37-45.

Randolph, G. (1984). Therapeutic and physical touch: Physiological response to stressful stimuii. Nursing Research, 33(1), 33-36.

Smith, J. (1972). Paranormal effects of enzyme activity. Human Dimensions, $1(10), 15-19$.

Tiller, W. A. (1982). Explanation of electrodermal diagnostic and treatment instruments: Part 1. Electrical behavior of human skin. Journal of Holistic Medicine, 4 (2), 105-127.

Tyler, H. \& Warfield, C. A. (1985). Thermography of pain: Instrumentation \& uses. Hospital Practice, 30, 164-169.

Wallace K. (1970). Physiological effects of transcendental meditation. Science, 167(27), 1751-1755.

Webster's Ninth New Collegiate Dictionary. (1988). Springfield, MA: Merriam-Webster.

Wirth, D. P. (1992). Unorthodox healing: The effects of non-contact therapeutic touch on the healing rate of full thickness dermal wounds. Unpublished manuscript. 
Wyatt, G. (1988). The balancing touch. Nursing Times, 84(21), 40-42.

Zimmerman, J. (1989). Biomagnetism attracts diverse crowd. Research News, 245(8), 1041-1043. 
APPENDICES 
APPENDIX A

PREQUESTIONNAIRE FOR DESCRIPTIVE INFORMATION AND PRETEST STRESS LEVEL RATING 


\section{PREQUESTIONNAIRE}

Questionnaire for Descriptive Information and Pretest Stress Level Rating Please answer the following questions:

1. Age:

2. Gender:

3. Weight:__ Height:

4. Any significant medical history or current problems:

5. Do you practice yoga on a regular basis for at least 30 minutes 3 times a week?

6. Do you meditate on a regular basis for at least 30 minutes 3 times a week?

7. Are you familiar with the procedure and practice of therapeutic touch?

8. On a scale of 1-10 ( 1 being low, 10 being high), please note level of stress prior to study and after study.

Prior to study:

After study: 
APPENDIX B

CONSENT FORM TO PARTICIPATE IN RESEARCH AT SAN JOSE STATE UNIVERSITY 


\section{a 2 SAN JOSE A STATE - $19 \mathrm{~S}$ S UNIVERSITY}

College of Applied Sciences and Arts - Department of Occupational Therapy

One Washington Square - San José. California 95192-0059

Main Office: 408/924-3070 - Fieldwork Office: 408/924-3078 - FAX: 408/924-3088

\section{Consent Form to Participate in Research at San Jose State University}

TITLE OF PROTOCOL: The Effects of Therapeutic Touch on the Parasympathetic Nervous System as Evidenced by Superficial Skin Temperature.

\section{WHO IS RESPONSIBLE FOR THE STUDY?}

This study was developed by Christine Tharnstrom, OTR, at California Pacific Medical Center, San Francisco, California and a masters degree candidate at San Jose State University, San Jose, California. Guy L. McCormack an occupational therapist and professor in the College of Applied Science and Arts is the second researcher. If needed, Professor McCormack can be contacted in Central Classroom Building 113 or at 408-924-3084. Christine Tharnstrom can be contacted at 415-750-6485 during working hours Monday through Friday.

\section{WHAT IS THE AIM OF THE STUDY?}

The aim of the study is to provide statistical evidence that non-contact therapeutic touch influences the parasympathetic nervous system along the meridian of the vagus nerve and will induce a relaxation response as evidenced by a rise in superficial skin temperature. This modality can be used as a viable adjunct to therapy in the field of occupational therapy to stimulate a relaxation response.

\section{WHYY WAAS I CHOSENY?}

You have been selected from the students at San Jose State University in the Occupational Therapy Department at random, based on accidental or availability sampling. We have used the Central Classroom Building as our selection site.

\section{WHAT WILL BE INVOLVED IN PARTICIPATING?}

I will be asked to lie supize on a cushioned table in a dimly lit room where the noise level will be minimal and the temperature controlled. I will lie with my clothes on and will be asked to close my eyes to lie still. Guy McCormack will hold his hands over my chest and naval area for 6 minutes, 3 to 8 centimeters from my body. I will have a sensory electrode taped to my abdomen to measure skin temperature which will be recorded on a computer. I will be asked to lie still for 4 minutes to establish a base line, receive the intervention, and lie still again for 4 minutes to conclude the study. I will be asked to wear an eye mask and ear muffs to decrease visual and auditory cues. I will have a cotton comforter over me and a pillow under my head and knees for comfort. 


\section{WHAT ARE MY RIGHTS AS A PARTICIPANT?}

Please feel free to ask any questions you wish about the experiment. Your participation is voluntary and you may withdraw at any time. Everything you say will be confidential and nothing you say will be identified with you personally. One hopes you will find the research process interesting enough to compensate for the time it takes to participate in the experiment.

\section{WHAT WUL HAPPEN TO THE INFORMATION?}

The information collected from the computer printout will be presented to a statistician to develop and correlate the data. The statistician will only use the participant's age and gender identification, and other information from the questionnaire for descriptive demographics; names are not necessary. The results of this study may be published, but any information from this study that can be identified with the participant will remain confidential.

\section{RISKS AND BENEFITS IN PARTICIPATION.}

The possible risks of this study are minimal. However, there is a possibility of falling asleep. No risks are anticipated. The possible benefits are to experience a sense of relaxation and calm.

This study has been reviewed and conforms to the by-laws adopted by the committee for the Protection of Human Subjects. Complaints about the procedures may be presented to Lela Llorens, Occupational Therapy Department Chairman and Graduate Coordinator at 408-924-3072. For qucstions about research subjects rights, or in the event of research related injury, contact Serena Stanford, Ph.D. (Associate Academic Vice President for Graduate Studies \& Research) at 408-924-2480.

I have read the above information and have decided to willingly participate as a subject for non-contact therapeutic touch research.

$\overline{\text { Participant's signature }} \overline{\text { Date }}$




\section{APPENDIX C}

\section{EXPERIMENTAL SUBJECTS’ BILL OF RIGHTS}




\section{EXPERIMENTAL SUBJECTS’ BILL OF RIGHTS}

The rights below are the rights of every person who is asked to be in a research study. As an experimental subject I have the following rights:

1. To be told what the study is trying to find out.

2. To be told what will happen to me and whether any of the procedures, drugs, or devices are different from what would be used in standard practice.

3. To be told about the frequent and/or important risks, side effects, or discomforts of the things that will happen to me for research purposes.

4. To be told if I can expect any benefit from participating and, if so, what the benefits might be.

5. To be told the other choices I have and how they may be better or worse than being in the study.

6. To be allowed to ask any questions concerning the study both before agreeing to be involved and during the course of the study.

7. To be told what sort of medical treatment is available if any complications arise.

8. To refuse to participate at all or to change my mind about participating after the study is started. This decision will not affect my right to receive the care I would receive if I were not in the study.

9. To receive a copy of the signed and dated consent form.

10. To be free of pressure when considering whether I wish to agree to be in the study.

If I bave other questions I should ask the researcher. In addition, I may contact the Fuman Subjects Institutional Review Board, which is concerned with protection of volunteers in research projects. I may reach the committee by calling: (408) 924-1438 from 8:00 AM to 5:00 PM Nionday through Friday, or by writing to the Human Subjects Institutional Review Board, San Jose State University Foundation, One Washington Square, San Jose, CA 95192-0139. 
APPENDIX D

POSTQUESTIONNAIRE AND POSTTEST STRESS LEVEL RATING 
POSTQUESTIONNAIRE

\section{Questionnaire for Descriptive Information}

1. How would you rate your level of stress after the study?

2. Did you see anything during the study? Yes No

3. Did you hear anything during the study? Yes No

4. Did you feel any hands on your body during the study? Yes No

Thank you for participation in this study $* * * * * * * *$ 
APPENDIX E

LETTERS OF PERMISSION FOR REPRINTING ILUSTRATIONS 
MEDICAL SOCIETY OF THE STATE OF NEW YORK 4:D LAKEVILLE ROAD, P.O. BOX 5404, LAKE SUCCESS. N.Y. $11042 \quad$ (516) 488-6100 FAX: (516) 488-1267

PERKISSION TO REPRODUCE JOURNAL ARTICLES

The Medical Society of the State of New York hereby gives: Christine Tharnstrom

permission to reproduce the article entitled :

The Direct Current Control System: A Link Between Environment $\&$ Organism

which appeared in the issue of the

New York State Journal of Medicine.

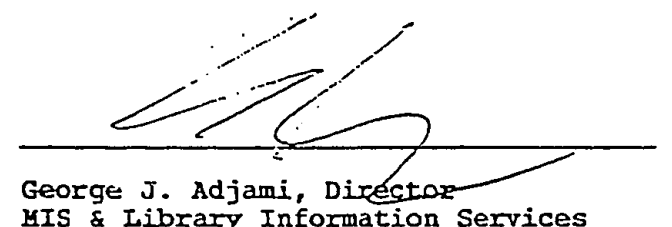

$4-21-93$

KIS \& Iibrary Information Services

Date 
$03 / 30 / 93 \quad 10: 58 \quad$ gig02 3250300 -

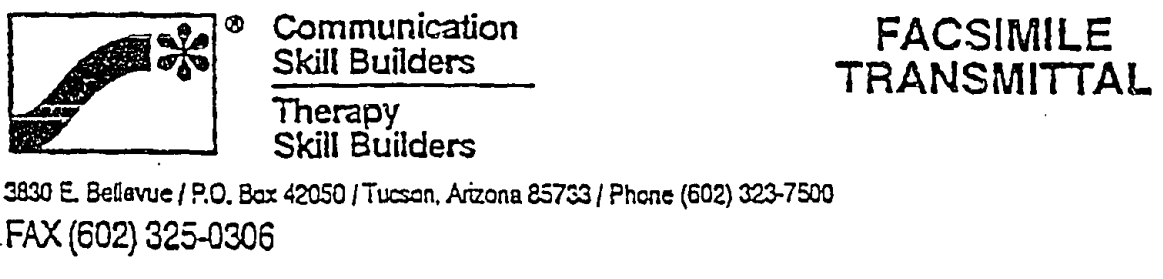

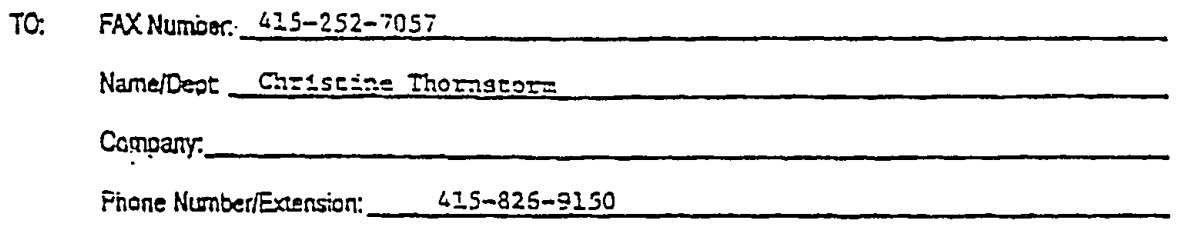

FRON: NamejDept Eivsa Soencer

Date:_Lareh 30,1993

Tctal pages (induding this sheet:

1

MESSAGE:

In response to your reques: of Marth 26, 1993. Therapy Skill Buiiders gives

Christine Thornstorm. permission to use two illustrations from THERAPEUTIC USE OF TOUCH by GuY McCormack in a thesis.

Flease print the following where the pages are used:

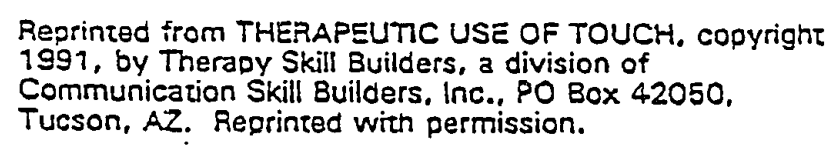

Please send us one copy of each of the complete pages on which these appear.

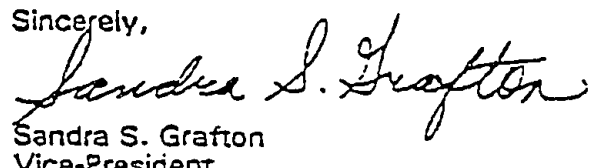

Vice-President

les 